\title{
Multiple-Factor Influence on Air Quality of Road Motor Vehicles Tail Number Limit in Administrative Area of Beijing, China
}

\author{
Bakhrom Rajabov (D), ${ }^{1}$ Lan Liu, ${ }^{1}$ and Jamshid Rajabov ${ }^{2}$ \\ ${ }^{1}$ School of Transportation and Logistics, Southwest Jiaotong University of China, Chengdu, Sichuan 610031, China \\ ${ }^{2}$ School of Automobile Roads and Artificial Structures, Tashkent State University of Transport of Uzbekistan, \\ Tashkent 100060, Uzbekistan \\ Correspondence should be addressed to Bakhrom Rajabov; bahrom.rajabov.2014@mail.ru
}

Received 4 April 2020; Revised 21 October 2020; Accepted 9 November 2020; Published 27 November 2020

Academic Editor: Yuchuan Du

Copyright (C) 2020 Bakhrom Rajabov et al. This is an open access article distributed under the Creative Commons Attribution License, which permits unrestricted use, distribution, and reproduction in any medium, provided the original work is properly cited.

\begin{abstract}
From December 2, 2013, to October 31, 2019 (total 2160 days), Beijing official air quality data was used as the research object. The article analyzes the end of days 4 and 9 and the end of the nonrestricted 4 and 9 days, working and nonworking days, restricted and nonrestricted working days, long holidays (Spring Festival and National Day), and nonlong holidays (short holidays other than the Spring Festival and National Day and working days) of AQI, PM2.5, PM10, $\mathrm{SO}_{2}, \mathrm{CO}, \mathrm{NO}_{2}$, and $\mathrm{O}_{3}$. According to the statistical analysis of the data, the air quality of the 4 and 9 limit is worse than that of the non- 4 and 9 limit. Motor vehicles restricted in traffic had an objective effect on air AQI, PM2.5, PM10, CO, and $\mathrm{NO}_{2}$, whereas there was almost no difference in $\mathrm{O}_{3}$. Some peak values of AQI, PM2.5, $\mathrm{PM} 10, \mathrm{SO}_{2}, \mathrm{CO}$, and $\mathrm{NO}_{2}$ on nonrestricted working days were significantly higher than those on restricted working days. At the same time, there was a peak time of the impact of motor vehicles on AQI, PM2.5, PM10, $\mathrm{SO}_{2}, \mathrm{CO}$, and $\mathrm{NO}_{2}$ in Beijing. This time should be between 3 and 5 days, or 72 and 120 hours.
\end{abstract}

\section{Introduction}

Air pollution is harmful to human health. To every country around the world, one of the environmental policy goals is to control air pollution for human health [1-3]. More than the center of China's political, economic, cultural, and international exchanges, Beijing gathered as a center at the regional level. The area of Beijing is $16410 \mathrm{~km}^{2}$. The total area of Beijing core area (District Dongcheng, District Xicheng) is $92 \mathrm{~km}^{2}$. The area of Beijing (plus function expansion area) is $1368 \mathrm{~km}^{2}$. After 2004, the urbanization process in Beijing continued to accelerate. The population and motor vehicles increased rapidly. The number of motor vehicles in Beijing reached 5.631 million by the end of 2017 .

According to several media estimates, the number of motor vehicles carrying licenses in Beijing was around 700,000 due to Beijing's policy of Motor vehicle restriction. The increasingly severe traffic congestion was turned into one of the major urban problems that plagued Beijing along with the rapid growth of the population and the number of motor vehicles.

In recent years, the number of motor vehicles in China has increased year by year. Motor vehicle exhausted pollution was an important source of urban air pollution [4]. As an integral part of the environmental policy to control air pollution, motor vehicle restriction is based on the vehicle tail number to restrict its traffic system and environmental policies according to certain rules. Motor vehicle restrictions had been implemented in such countries in the world as Mexico City, São Paulo in Brazil, Bogota in Colombia, and Santiago in Chile. In March 2014, the concentration of PM10 of Paris was still exceeding the standard for five consecutive days and reached a record peak of $180 \mathrm{mg} / \mathrm{m}^{3}$ micrograms per cubic meter when Paris first announced the restriction of motor vehicle tails. Subsequently, Paris implemented the single- and double-limit measures for motor vehicle trailers. This was the first time France has implemented single- and double-limit measures for motor vehicle trailers since 1997. 
Since 2008, China has implemented motor vehicle restriction policies in Beijing, Lanzhou, Guiyang, Hangzhou, Chengdu, Changchun, Tianjin, Wuhan, Harbin, Jinan, Nanchang, and other cities. Beijing and Xi'an are still implementing motor vehicle restriction policies by tail number. Beijing limit line was mainly focused on the regular periodic tail number limit. At the same time, Beijing once carried out single and double number restrictions several times: (1) from July 1 to September 20, 2008, Beijing Olympics, Paralympic Games; (2) 2014 Beijing APEC, from November 3 to November 12, tail number single/double limited; (3) from August 20 to September 3, 2015, the military journals limited to single/double tail number; and (4) from December 16, 2016, Beijing implementing single and double tail number limit for heavy pollution red warning.

With the double-difference method, Tanaka analyzed the impact of the Chinese air pollution control policy on infant mortality in 1998 [5]. It was found that air pollution control policies significantly reduced infant mortality [6]. Whether or not environmental policies can reduce air pollution is a common concern. Therefore, assessing the effectiveness of policies to control air pollution was a research hotspot in the theoretical world. The effects of water pollution control policies and air pollution control policies in India were compared by Greenstone and Hanna; they found that air pollution control policies significantly improved air quality and water pollution control policies had little effect [7]. The effect of gasoline content control policies implemented by California was evaluated by Aufhammer and Kellogg as well as two other federal governments on reducing $\mathrm{O}_{3}$; they found that two federal policies had no significant effect on reducing $\mathrm{O}_{3}$ other than those implemented by California [8]. The impact of the increase in motor vehicle emission standards on improving air quality was tested with the breakpoint regression method by Sun Kunxin; it was found that the implementation of the new standard significantly reduced the average PM 2.5 concentration in Beijing [9].

On a macroscale, the tail numbers $0-9$ are random equal distributions. However, too few car owners chose 4 due to the homophony of 4 and "dead" in Chinese culture. In recent years, Beijing traffic administration once excluded 4 from the license plate library for new selection [10].

In view of this, this study used a starting point from December 2, 2013 (since Beijing has its own air records) to October 31,2019 , and a total of 2,160 days as object. The influence of the short-term motor vehicle restriction on the quality of empty grips was taken as the research object. At the same time, the difference between the number of 4 and 9 restriction days and the number of restricted non- 49 days was considered. The difference between working-day (some working days are not restricted) holidays (all unrestricted lines) was analyzed as well as the difference between restricted working days. What is more, the difference between long holidays (National Day and Spring Festival, 7-day holiday) was distinguished with nonlong holidays (continuous leave less than 7 days). The motor vehicle traffic restrictions studied in this paper do not consider the interference of alternative driving by the owner during nontraffic days during the traffic restrictions. At the same time, the driving force and possibility of car owners to purchase another motor vehicle to evade the traffic restriction policy have also declined significantly in the short term.

Based on the above, the double-difference model was used under the quasi-experimental framework to analyze. Numbers 4 and 9 restricted days, working days (some working days not restricted), restricted working days, and long holidays (National Day and Spring Festival, 7 days) were set as the treatment group with the corresponding non4 and 9 restricted line days, holidays (all unrestricted lines), unrestricted working days, and nonlong leave (continuous vacation less than 7 days) as the control group. Among them, AQI, PM2.5, PM10, $\mathrm{SO}_{2}, \mathrm{CO}, \mathrm{NO}_{2}, \mathrm{O}_{3}\left(\mathrm{O}_{3}-8 \mathrm{~h}\right.$, first 8 hours), and other changes were separately analyzed under related circumstances.

In the first part of the article, the influencing factors were analyzed with air quality. Such parameters as AQI, $\mathrm{PM}$ 2.5, $\mathrm{PM} 10, \mathrm{SO}_{2}, \mathrm{CO}, \mathrm{NO}_{2}$, and $\mathrm{O}_{3}$ summarized the changes at different times. In the second part, the study design was given as well as model settings. The third part introduced the data used in this article and the AQI, PM2.5, PM10, $\mathrm{SO}_{2}, \mathrm{CO}, \mathrm{NO}_{2}$, and $\mathrm{O}_{3}$ were analyzed in such specific circumstances with working days (some working days are not restricted), restricted working days, and long holidays (National Day and Chinese New Year, 7 days off) as a processing group, corresponding to tail number non-4 and 9 restricted days. The third part introduced the data used in this article. AQI, PM2.5, PM10, $\mathrm{SO}_{2}, \mathrm{CO}, \mathrm{NO}_{2}, \mathrm{O}_{3}$ was analyzed in such four specific group circumstances: tail number 4 and 9 and tail number non-4 and 9 (5.1), working days and nonworking days (5.2), restricted working days and nonrestricted working days (5.3), and long holidays and non-long holidays (5.4). The fourth part analyzed the changing rules and influencing factors of AQI during the period of 0-24 hours from September 01, 2019, to October 31, 2019. The fifth part is the conclusion of the study.

\section{Design and Model}

The dynamic factor model is a generalization and development of the traditional factor model in time series. The dynamic factor model is good at processing data with the number of observation time points greater than the number of observation variables [11]. With the dimension of the observation, the factor loading matrix of the observation equation is often a sparse matrix when the variable is high and the influence of the factor is limited.

2.1. Impact Factors of Air Quality. According to the data source and content analysis data, the following factors determine the impact factors of air quality (Table 1).

2.2. Air Quality Fluctuation Model. It is assumed that the number of factors is $q=9,12,14$, respectively. From this view, the parameter was estimated as the air quality rate model. It can be referred that the public factors were positively correlated with most of the air quality fluctuations. 
TABLE 1: Impact factors of air quality.

\begin{tabular}{lcc}
\hline Number & Impact factor & Effect \\
\hline 1 & Time-year & Periodic change, overall decline \\
2 & Time-month & Cyclic change \\
3 & Time-day & Cyclic change \\
4 & Time & Fluctuations \\
5 & Weather & Classification change \\
6 & Industrial emissions & Linear relationship \\
7 & Opportunity cars & Linear \\
8 & Oil and gas quality & Inverse function \\
9 & $\mathrm{PM} 2.5$ & Partially positive \\
10 & $\mathrm{PM} 10_{10}$ & Partially positive \\
11 & $\mathrm{SO}_{2}$ & Partially positive \\
13 & $\mathrm{CO}_{1}$ & Partially positive \\
14 & $\mathrm{NO}_{2}$ & Partially positive \\
\hline
\end{tabular}

2.3. Common Factors. Most of the elements of the factor load matrix are nonzero. The following are the first five nonzero elements (sorted by absolute value), their corresponding months, and related impact parameters. It can be referred that this common factor partially affecting air quality was called a common factor. The line graph of the common factor over time was a sine function with a decreasing amplitude.

Preliminary calculations showed that the common factor fluctuates significantly downward in multiple graphs. The fluctuations were relatively small at other times. Judging from the actual situation of the Chinese government in recent years, air quality was significantly improved because multiple measures were introduced by the Chinese government in recent years. These measures may be implemented through industrial restrictions on emissions, control of the number of opportunity cars, and control of oil and gas quality. At the same time, the impact of weather on air quality is consistent with seasonal climate fluctuations. It is undeniable that such fluctuations in air quality are consistent with weather as well as the participation of human-induced changes in weather.

\section{Model Settings}

The model settings in this article are based on the benchmark models published by Liu Ying and Zhang Ying with slight modifications [12]. In contrast, the panel fixed effect model does not need this assumption, and the Hausman test also supported the use of the panel fixed effect model for estimation. This paper used the panel fixed effect model to estimate the model setting. The following benchmark model was established within the framework of a dual differential mode to measure the impact of motor vehicle restrictions on improving air quality:

$$
P_{\mathrm{it}}=m_{t}+c_{t}+\sum_{1}^{\mathrm{n}} \beta_{\mathrm{n}} \times T_{\mathrm{nt}}+\varepsilon_{\mathrm{it}} .
$$

Among which, variable $P_{i t}$ is an air pollution indicator variable. $P_{i t}$ represents five air pollutants $\left(\mathrm{SO}_{2}, \mathrm{NO}_{2}\right.$, $\mathrm{PM} 10, \mathrm{CO}$, and $\mathrm{O}_{3}$ ) and air pollution index (API) routinely monitored in China. $M_{t}$ represents the fixed effect of time to control the macrochanges facing all cities. $C_{i}$ represents the urban fixed effect to control heterogeneous characteristics between cities that do not change over time. $\varepsilon_{i t}$ is a random perturbation term. $T_{\mathrm{nt}}$ is a dummy variable representing the period of quasi-experiment. In this article, the overall effect of improving the air quality was first analyzed during the restricted period in the past 6 years. At the same time, each factor in the sample was analyzed independently. Such restriction as weather when the model sets and the 4-and-9-day limit date This article was not taken into account as well as non4 and 9-day limit date. When analyzing the difference between a working day and a holiday (all unlimited lines), it did not consider whether the working days are restricted or not (some working days were not restricted). When analyzing the restricted working days and unrestricted working days, the number of restricted lines was not considered as well as categories (e.g., single and double number restrictions, 4 and 9 restrictions, or other restrictions). When analyzing the difference between long holidays (National Day and Spring Festival, 7-day holiday) and nonlong holidays (continuous holidays less than 7 days), other traffic controls or tail numbers were not considered. Therefore, the cross-term coefficient $\beta_{\mathrm{n}}$ of $J_{i}$ and $T_{\mathrm{nt}}$ was the coefficient of most concern in this paper. It measured the air pollution in the treatment group and the control group during the quasi-experiment period of the motor vehicle restriction policy. The relative changes of indicators reflect the net effect of the traffic restriction policy implemented by the group cities on reducing air pollution indicators, improving air quality and the duration of the policy effect. This paper adds the control variable vector Xit on the basis of the benchmark model to obtain the extended model [2]. For the dual difference model, the base model [1], to achieve unbiased even without adding control variables estimation [2], to reflect the qualitative characteristics of urban time variability was added. It can reduce the variance of the estimation and improve the accuracy of the estimation. Both the benchmark model and the extended model were estimated to ensure the robustness of the conclusion:

$$
P_{\mathrm{it}}=m_{t}+c_{t}+\sum_{1}^{\mathrm{n}} \beta_{\mathrm{n}} \times T_{\mathrm{nt}}+\varepsilon_{\mathrm{it}}+X_{\mathrm{it}} \times \lambda .
$$

Among them, $X_{\mathrm{it}}$ is a control variable vector. It included weekend dummy variables, legal holiday dummy variables, and meteorological variable vectors.

\section{Explanation and Statistics}

4.1. Data Description. Such four-category data as air pollution indicator data and meteorological indicator data were included as well as weekend and weekend data and socioeconomic data. The air pollution indicator data, meteorological indicator data, and weekend and weekend data were daily data. The time span was from December $2^{\text {nd }}, 2013$, to October $31^{\text {st }}, 2019$ (2160 days). 
4.1.1. Air Pollution Indicator Data. The air pollution index data included daily averages of such five main air pollutants as $\mathrm{PM}$ 2.5, $\mathrm{PM} 10, \mathrm{SO}_{2}, \mathrm{CO}, \mathrm{NO}_{2}$, and $\mathrm{O}_{3}$ concentrations and the air pollution index AQI, routinely monitored in China. Data came from the website of the Ministry of Ecology and Environment https://www.aqistudy.cn/.

4.1.2. Weekend and Legal Holiday Data. Due to the fact that air quality would be affected by company's production behavior and people's lifestyle, accompanied by the adjustment of holidays and weekends, the effects of holidays and weekends were included in the model settings of this paper. The data of holidays and weekends came from the notice of holiday arrangements issued by the General Office of Chinese State Council.

4.2. Statistics. There were 2,160 days starting from December 2, 2013, to October 31, 2019. Samples were counted according to the 4-and-9-line restriction day and the non-4 and 9-line restriction day, the working day (some working days not restricted) and holidays (all unlimited lines), the restricted working day and the unrestricted working day, consider long holidays (National Day and Spring Festival, holidays, 7 days), and nonlong leave (continuous vacation less than 7 days). Software SPSS was used to Pearson correlation analysis with $\mathrm{AQI}, \mathrm{PM} 2.5, \mathrm{PM} 10, \mathrm{SO}_{2}, \mathrm{CO}$, and $\mathrm{NO}_{2}$ of tail number of 4 and 9 days and tail numbers non- 4 and 9 day.

\section{Results}

5.1. Tail Number of 4 and 9 and Tail Numbers Non-4 and 9. In the sample case of 2,160 days, tail number of 4 and 9 days totaled 283 days, accounting for $13.1 \%$ of the statistical day. Tail number non- 4 and 9 days totaled 1138 days, accounting for $52.7 \%$ of the statistical day. Tail number of 4 and 9 limit days: tail number non- 4 and 9 days $=1: 4.02$. Among them, tail number of 4 and 9 days, AQI maximum was 450, PM2.5 maximum was 353 , PM10 maximum was $550, \mathrm{SO}_{2}$ maximum was $118, \mathrm{CO}$ maximum was $6, \mathrm{NO}_{2}$ maximum value was 125 , and the maximum value of $\mathrm{O}_{3}$ was 294. AQI average was 98.73, PM2.5 average was 59.53, PM10 average was $84.23, \mathrm{SO}_{2}$ average was $10.30, \mathrm{CO}$ average was $1.02, \mathrm{NO}_{2}$ average was 45.35 , and $\mathrm{O}_{3}$ average was 92.83 (Table 1 ).

Among them, the maximum tail number of non-4 and 9 days of AQI was 500: PM2.5 maximum 477, PM10 maximum 510, $\mathrm{SO}_{2}$ maximum 133, $\mathrm{CO}$ maximum $8, \mathrm{NO}_{2}$ maximum 155, and $\mathrm{O}_{3}$ maximum 311 . The average AQI was 105.40: average PM2.5 62.98, average PM10 89.01, average $\mathrm{SO}_{2} 10.42$, average $\mathrm{CO} 1.03$, average $\mathrm{NO}_{2} 45.84$, and the average $\mathrm{O}_{3} 00.52$ (Table 2).

In the period of 2014-2019, except for $\mathrm{O}_{3}$, AQI, PM2.5, $\mathrm{PM} 10, \mathrm{SO}_{2}, \mathrm{CO}$ and $\mathrm{NO}_{2}$ all showed markedly gradual wave decline $(p<0.01)$ (Figure 1). One high degree of consistency was showed with Beijing Municipal Government's control of Beijing air quality through fuel oil, coal burning $(p<0.01)$. That the performance of $\mathrm{O}_{3}$ was relatively stable indicated that $\mathrm{O}_{3}$ production was relatively independent of these human factors! Except for $\mathrm{O}_{3}$, some peaks of the dynamic performance of AQI, PM2.5, $\mathrm{PM} 10, \mathrm{SO}_{2}, \mathrm{CO}$, and $\mathrm{NO}_{2}$ with tail number of 4 and 9 were higher than those with tail number of non-4 and $9(p<0.05)$. Results showed that the overall effect of Beijing Municipal Government on its air quality control achieved certain results $(p<0.05)$. The tail number of 4 and 9 of AQI, PM2.5, PM10, $\mathrm{SO}_{2}, \mathrm{CO}$, and $\mathrm{NO}_{2}$ dynamics was significantly worse than that of non-49-line limit $(p<0.05)$.

5.2. Working Days and Nonworking Days. In the sample cases, working days totaled 1535 days, accounting for $68.68 \%$ of the candidate days. Nonworking days totaled 700 days, accounting for $31.32 \%$ of the candidate days. Working days: nonworking days $=2.20: 1$. Among them, the maximum AQI of working days was 500, the maximum value of PM2.5 was 477, the maximum value of PM10 was 550, the maximum value of $\mathrm{SO}_{2}$ was 1133 , the maximum value of $\mathrm{CO}$ was 8 , the maximum value of $\mathrm{NO}_{2}$ was 155 , and the maximum value of $\mathrm{O}_{3}$ was 311. AQI average value was 103.93, PM2.5 average value was 62.28, PM10 average value was 88.08, $\mathrm{SO}_{2}$ average value was $10.46, \mathrm{CO}$ average value was $1.03, \mathrm{NO}_{2}$ average value was 45.69 , and $\mathrm{O}_{3}$ average value was 98.27. Among them, nonworking day AQI maximum value was 470 , PM2.5 maximum value was 454 , PM10 maximum value was $512, \mathrm{SO}_{2}$ maximum was $130, \mathrm{CO}$ maximum was 8 , $\mathrm{NO}_{2}$ maximum was 141 , and $\mathrm{O}_{3}$ maximum was 270 . The average AQI was 112.48, PM2.5 was 69.78, PM10 was 95.37, $\mathrm{SO}_{2}$ was $11.17, \mathrm{CO}$ was $1.11, \mathrm{NO}_{2}$ was 45.50 , and $\mathrm{O}_{3}$ was 98.13 (Table 3).

During 2014-2019 (all working days and all nonworking days, and/or) and all air quality indicators AQI, PM2.5, $\mathrm{PM} 10, \mathrm{SO}_{2}, \mathrm{CO}, \mathrm{NO}_{2}, \mathrm{O}_{3}$ have shown clear and progressive wave-like decreasing, generally $(p<0.05)$ (Figure 2). Except for $\mathrm{O}_{3}$ and $\mathrm{SO}_{2}$, the peak values of AQI, PM2.5, PM10, CO, and $\mathrm{NO}_{2}$ in the nonworking day group were significantly higher than those in the working day $(p<0.05)$. From this point of view, it was clear that the performance of $\mathrm{O}_{3}$ was not significantly different between working days and nonworking days $(p<0.05)$. It was indicated that $\mathrm{O}_{3}$ production was relatively independent of those human factors!

\subsection{Restricted Working Days and Nonrestricted Working} Days. In the sample cases, the total number of working days was 1547 days, accounting for $98.00 \%$ of the statistical days. The nonlimiting working days were 31 days, accounting for $2.00 \%$ of the statistical days. Restricted working days: nonrestricted working days $=49: 1$. Of the restricted working days AQI maximum was 500, PM2.5 maximum was 477, PM10 maximum was 550, $\mathrm{SO}_{2}$ maximum was $133, \mathrm{CO}$ maximum was $8, \mathrm{NO}_{2}$ maximum was 155 , and $\mathrm{O}_{3}$ maximum was 311 . The average AQI was 104.46 , the average PM2.5 was 62.72, the average PM10 was 88.26, the average $\mathrm{SO}_{2}$ was 10.37 , the average $\mathrm{CO}$ was 1.04 , the average $\mathrm{NO}_{2}$ was 45.81 , and the average $\mathrm{O}_{3}$ was 98.42 .

Among them, the maximum AQI for nonrestricted working days was 334, the maximum value of PM2.5 was 284 , the maximum value of PM10 was 308 , the maximum 
Table 2: Pearson correlation analysis of restricted days with non-4 and 9 restricted days.

\begin{tabular}{|c|c|c|c|c|c|c|}
\hline & \multicolumn{2}{|c|}{ Peaks and valleys $(n)$} & \multirow{2}{*}{$R^{2}$} & \multirow{2}{*}{ Pearson correlation coefficient } & \multirow{2}{*}{$X^{2}$} & \multirow[b]{2}{*}{$p$} \\
\hline & Tail number of 4 and 9 days & Tail number of non-4 and 9 days & & & & \\
\hline AQI & 6 & 6 & 0.6835 & 12.0887 & 0.6672 & \\
\hline PM2.5 & 6 & 6 & 0.7046 & 4.6509 & 0.6123 & \\
\hline PM10 & 6 & 6 & 0.5995 & 17.6523 & 0.5052 & \\
\hline $\mathrm{SO}_{2}$ & 6 & 6 & 0.7593 & 11.8825 & 0.1913 & \\
\hline $\mathrm{CO}$ & 6 & 6 & 0.6341 & 22.7531 & 0.6329 & $<0.01$ \\
\hline $\mathrm{NO}_{2}$ & 6 & 6 & 0.6351 & 15.6144 & 0.8259 & $<0.05$ \\
\hline $\mathrm{O}_{3} \_\mathrm{h}$ & 6 & 6 & 0.6665 & 35.1589 & 0.1806 & $>0.05$ \\
\hline
\end{tabular}

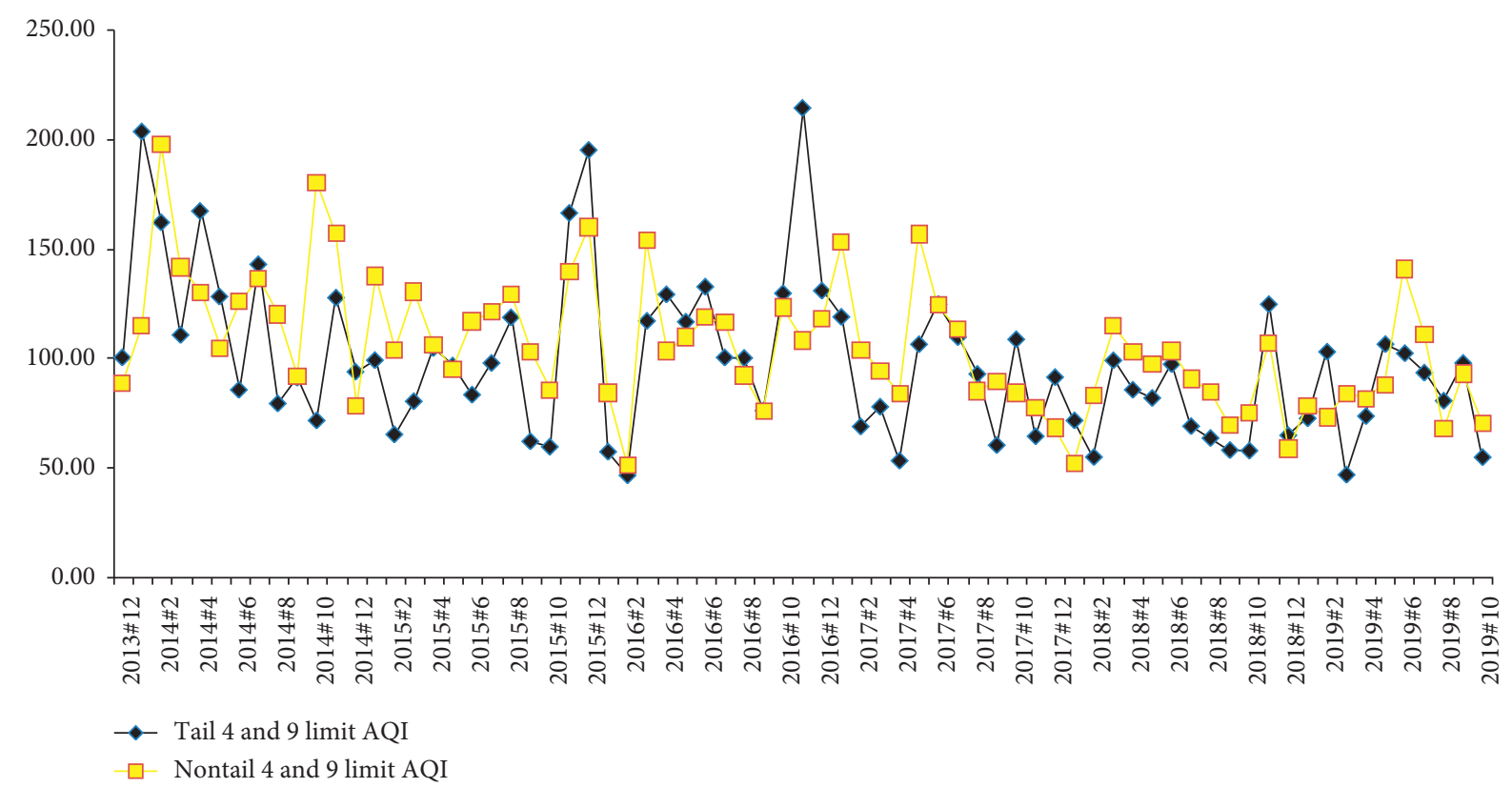

(a)

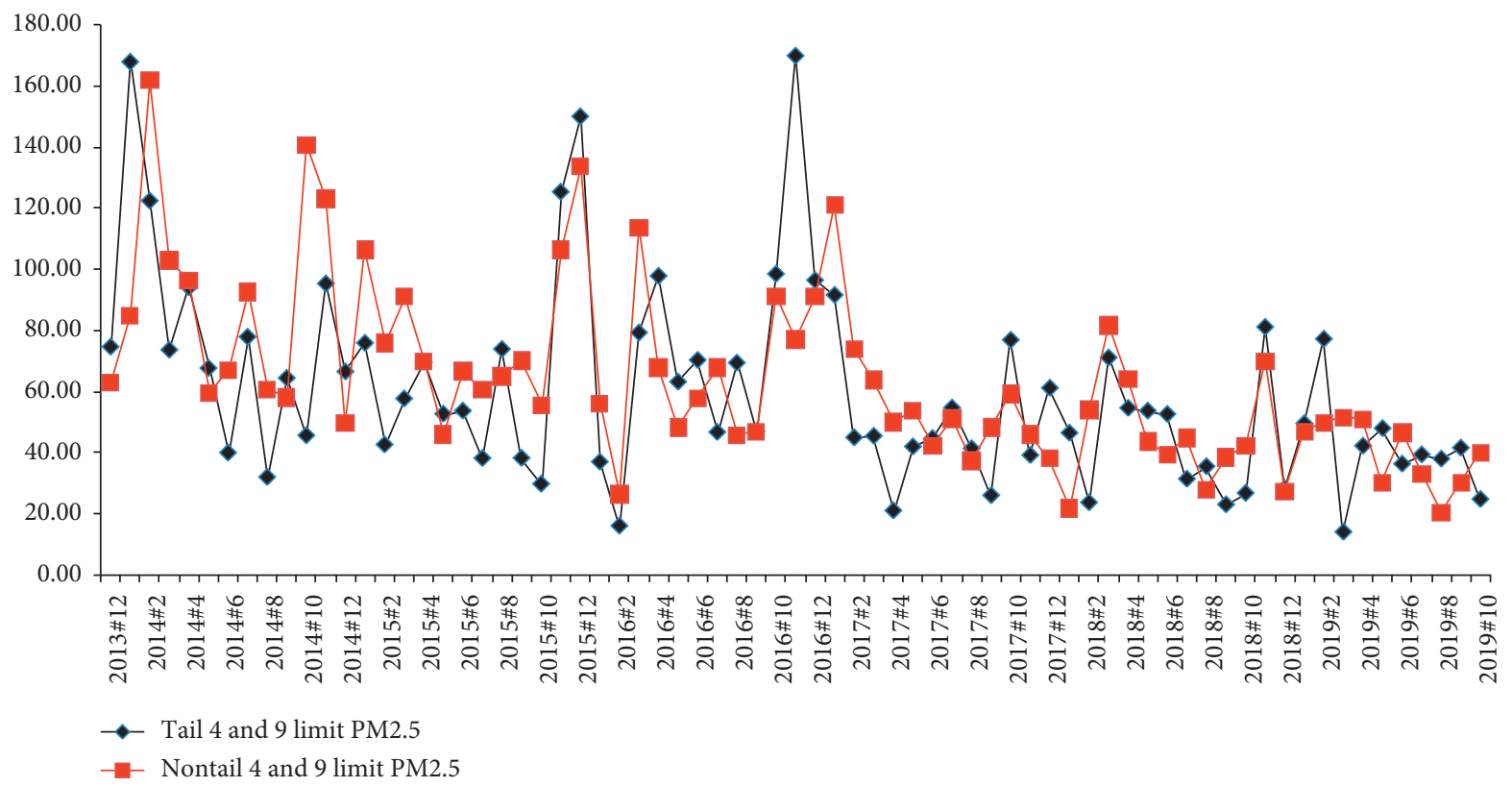

(b)

Figure 1: Continued. 


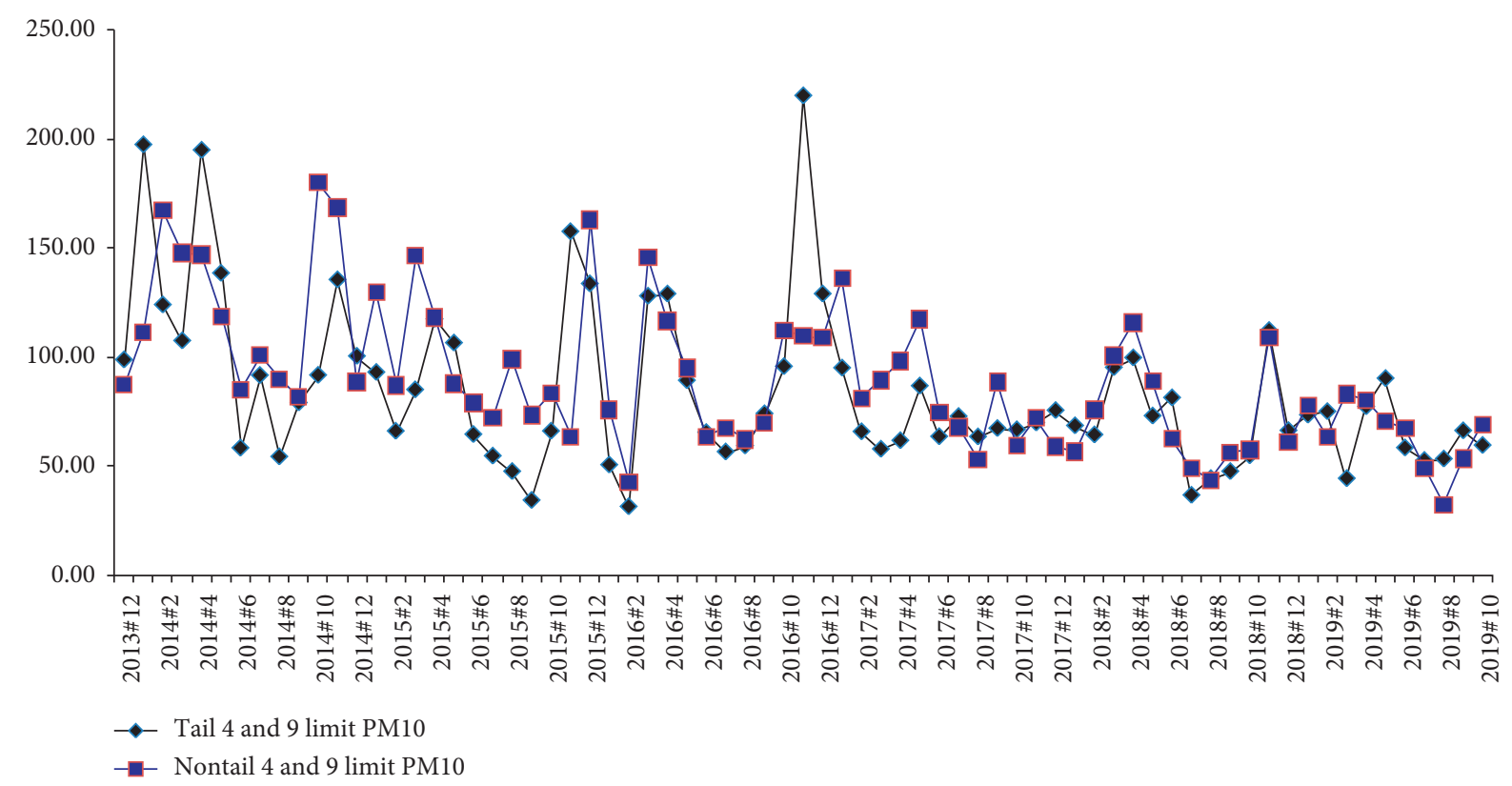

(c)

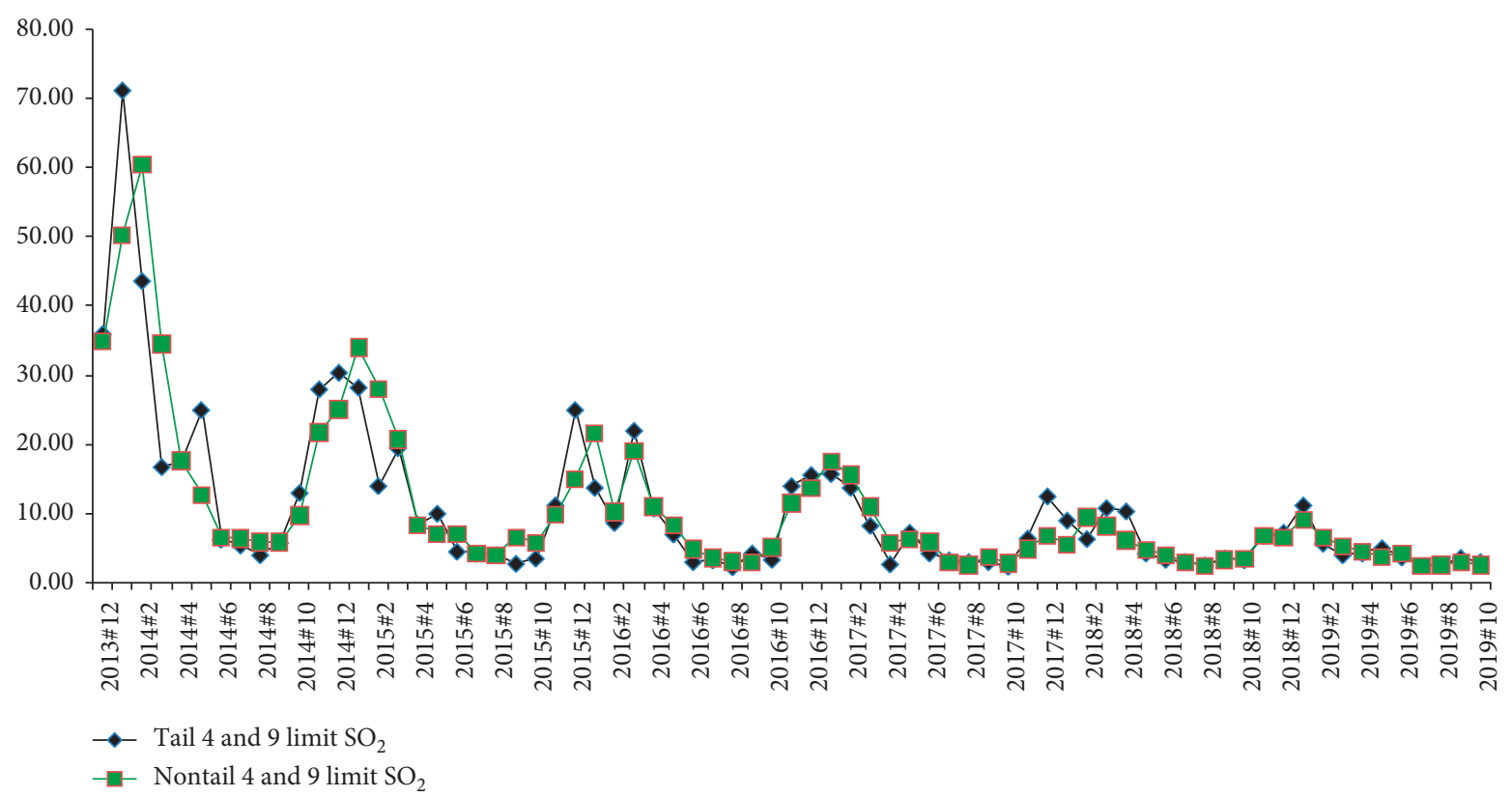

(d)

Figure 1: Continued. 


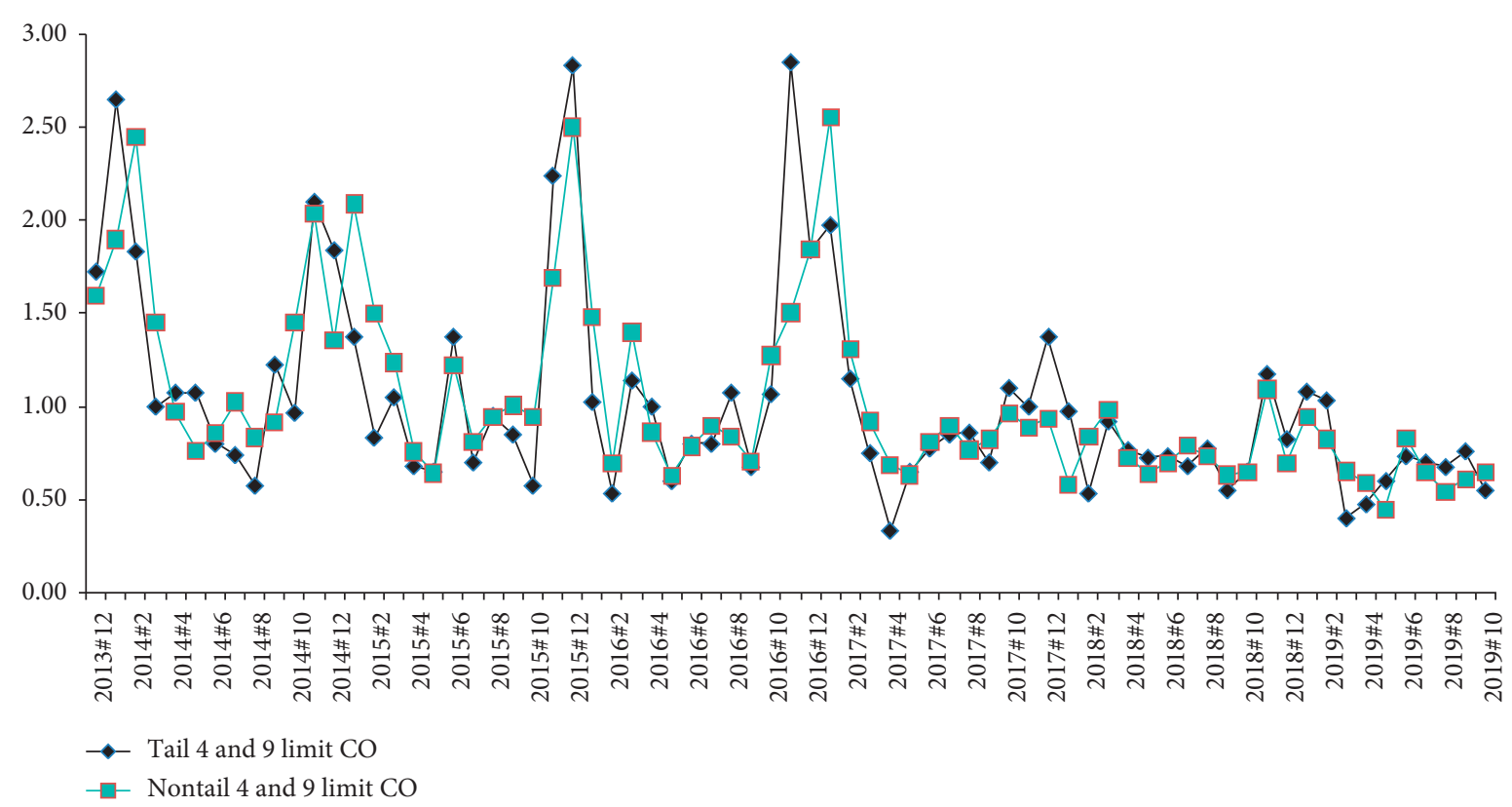

(e)

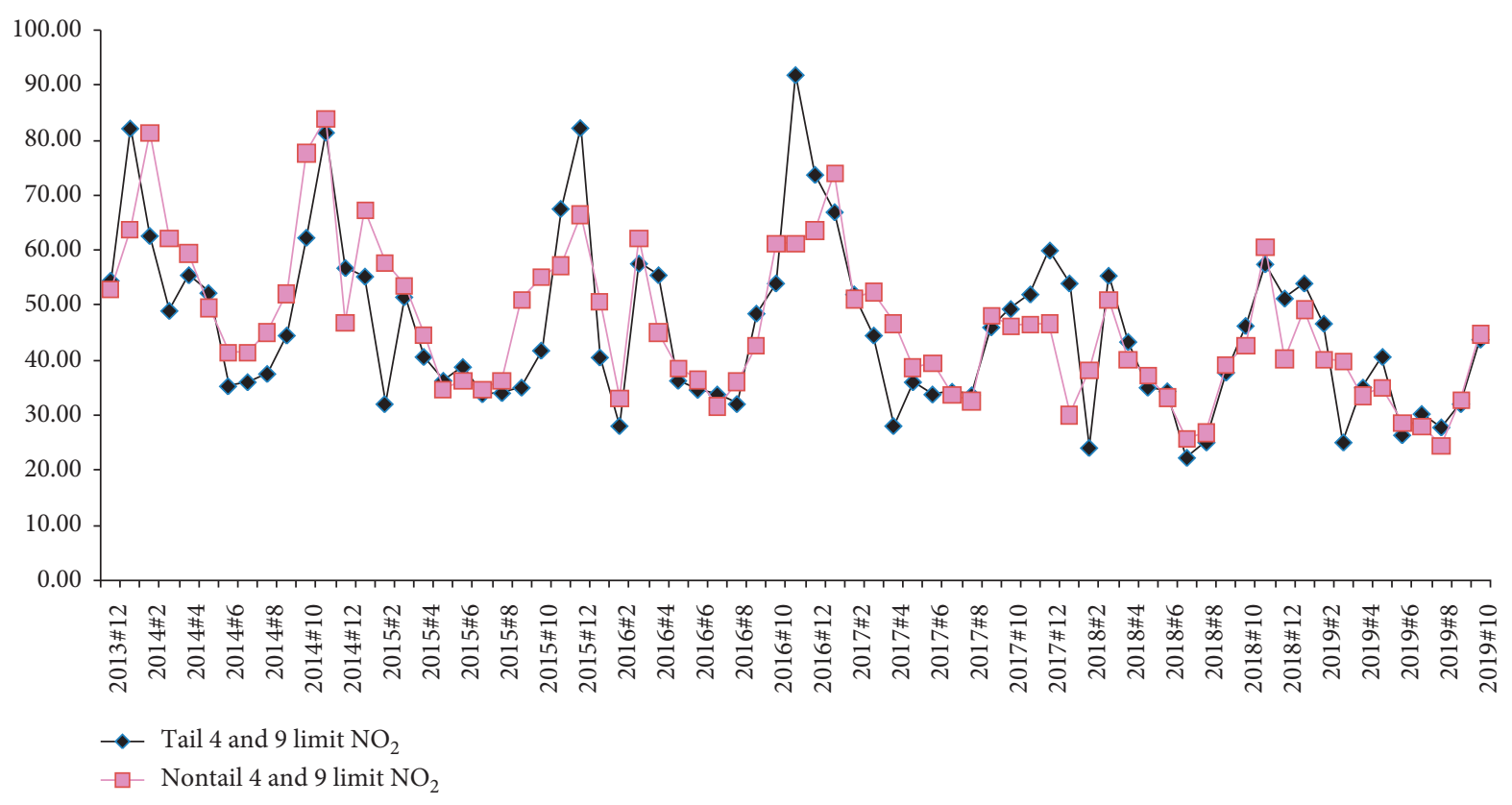

(f)

FIGURE 1: Continued. 


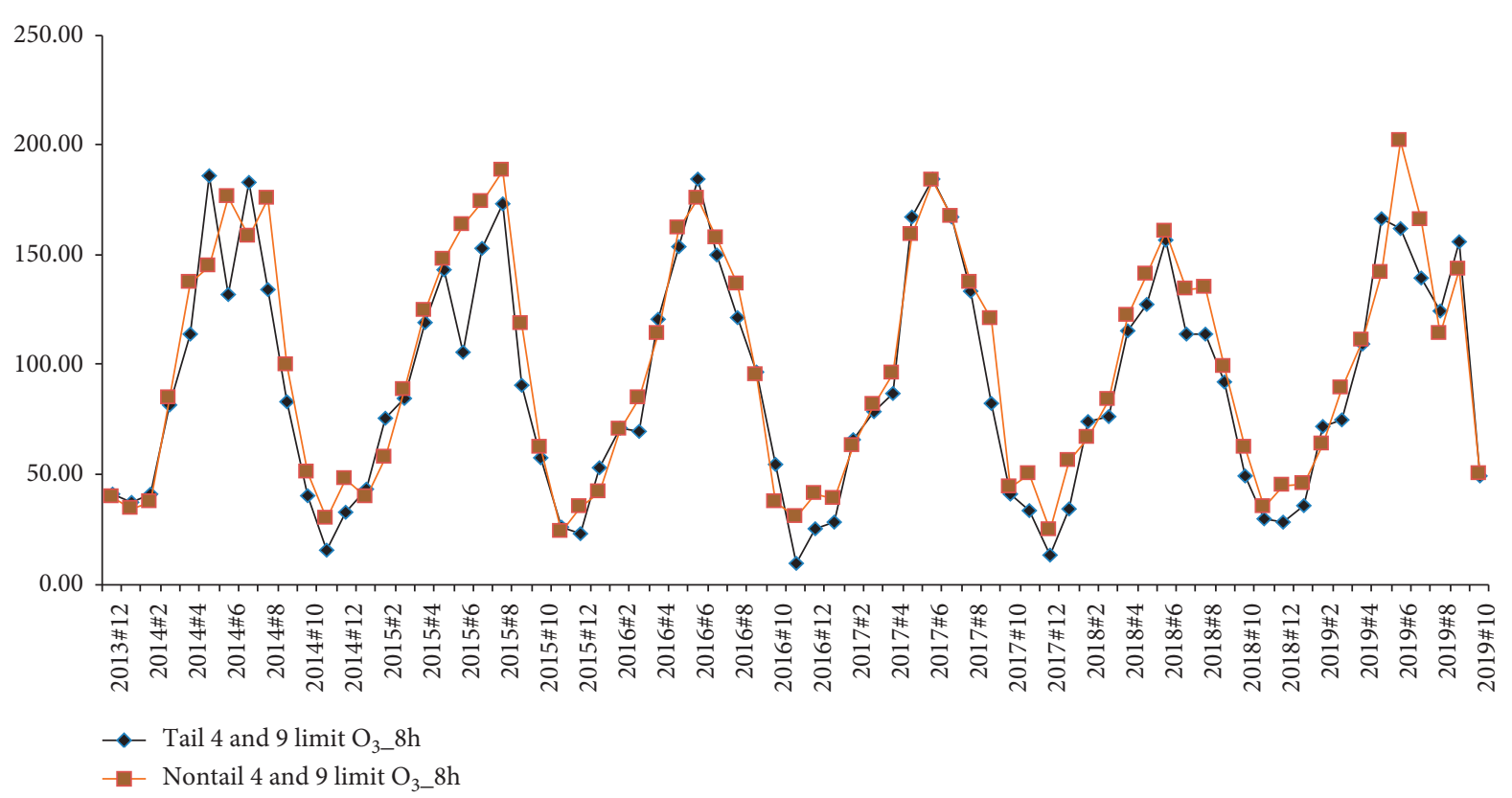

(g)

FIgURE 1: Comparison with the tail number of 4 and 9 and tail number of non-4 and 9 .

TABLE 3: Pearson correlation analysis of working days and nonworking days.

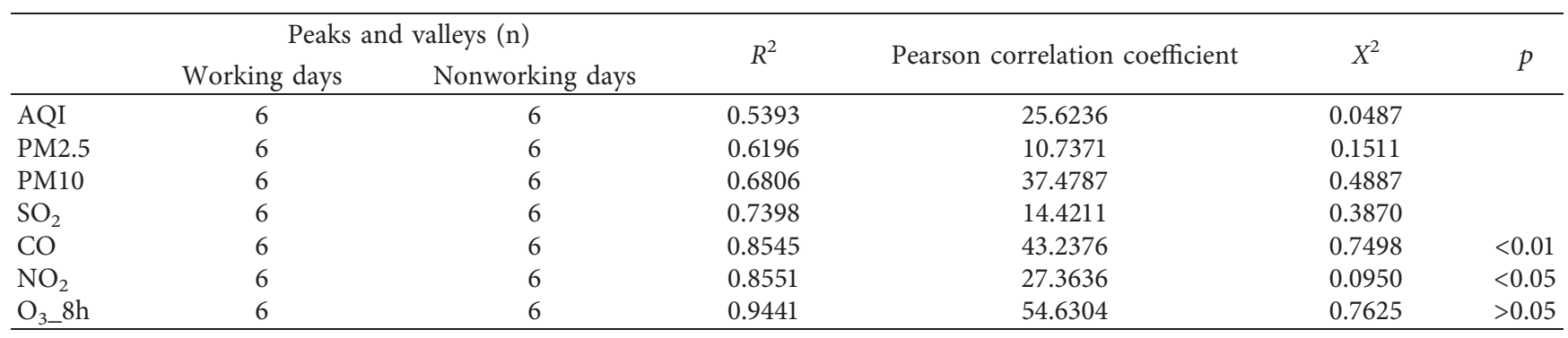

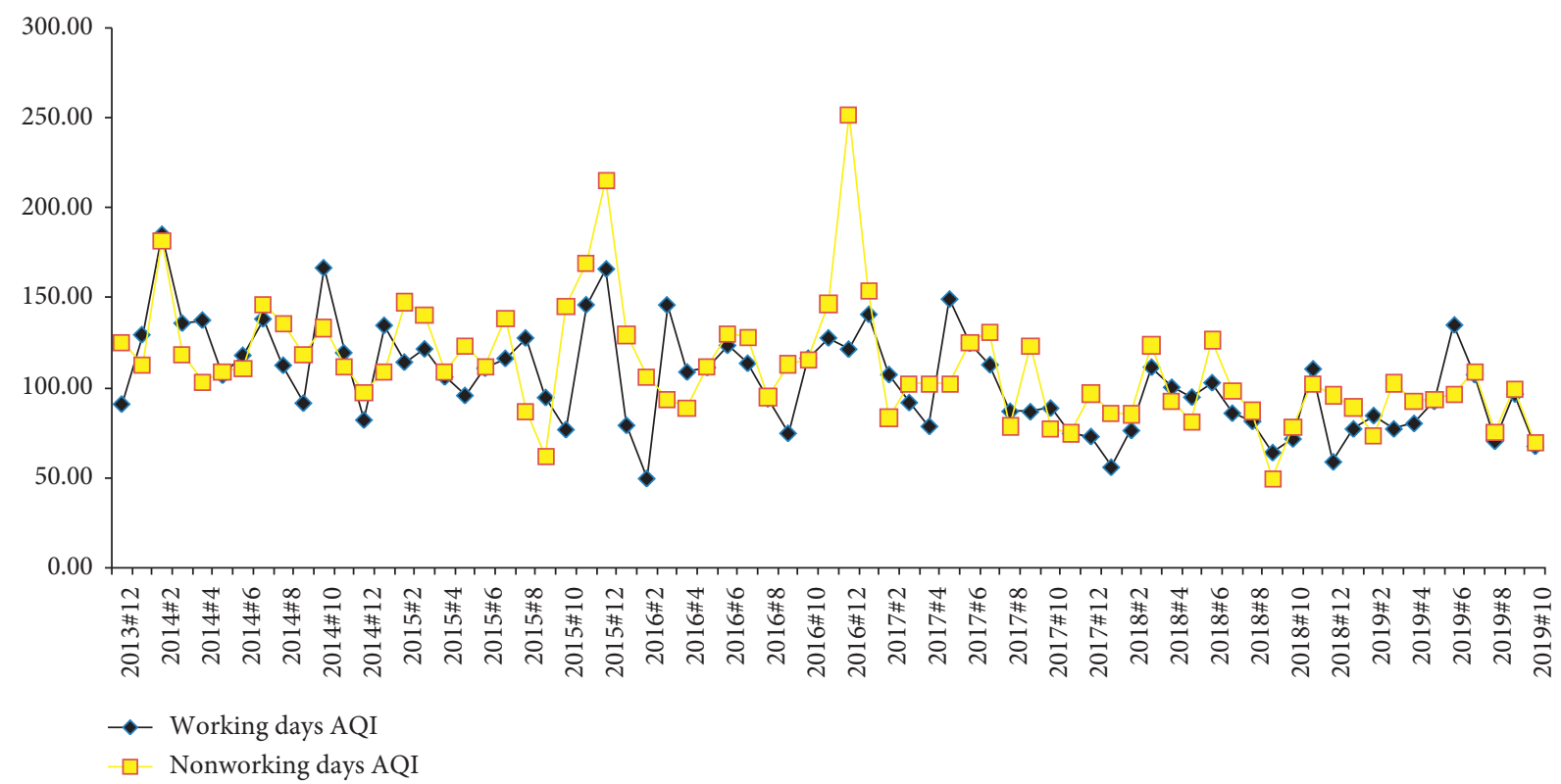

(a)

Figure 2: Continued. 


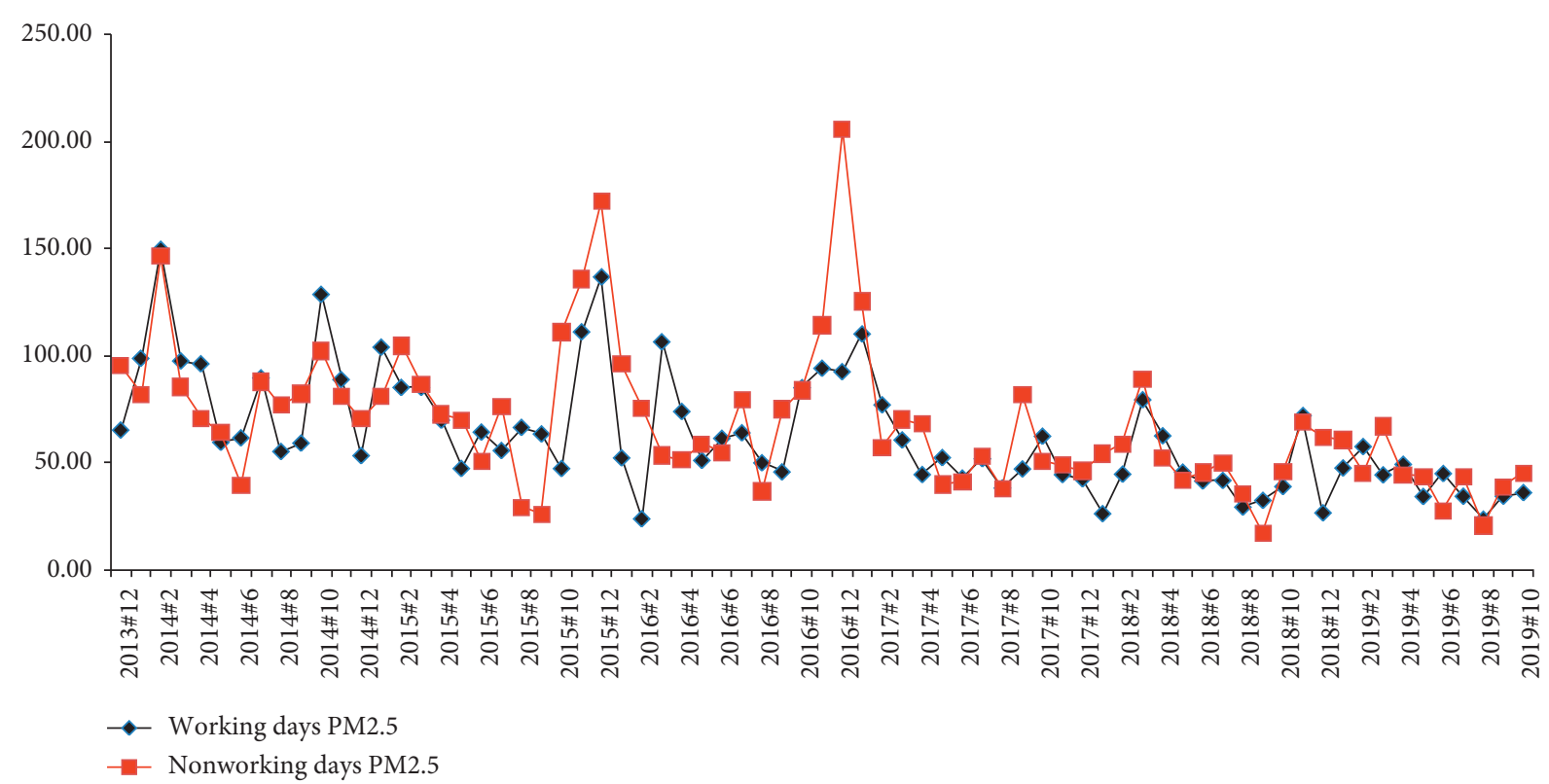

(b)

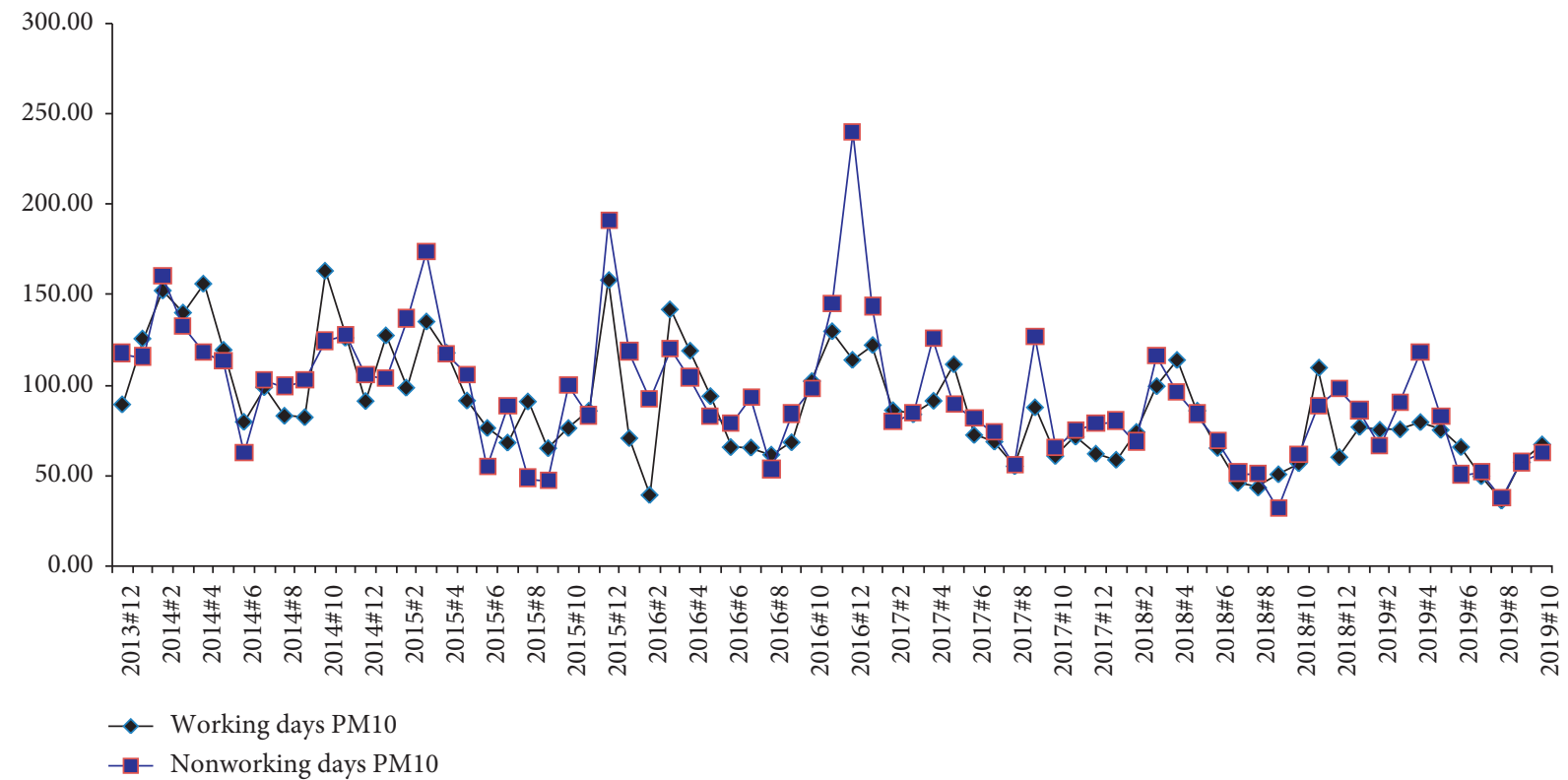

(c)

Figure 2: Continued. 


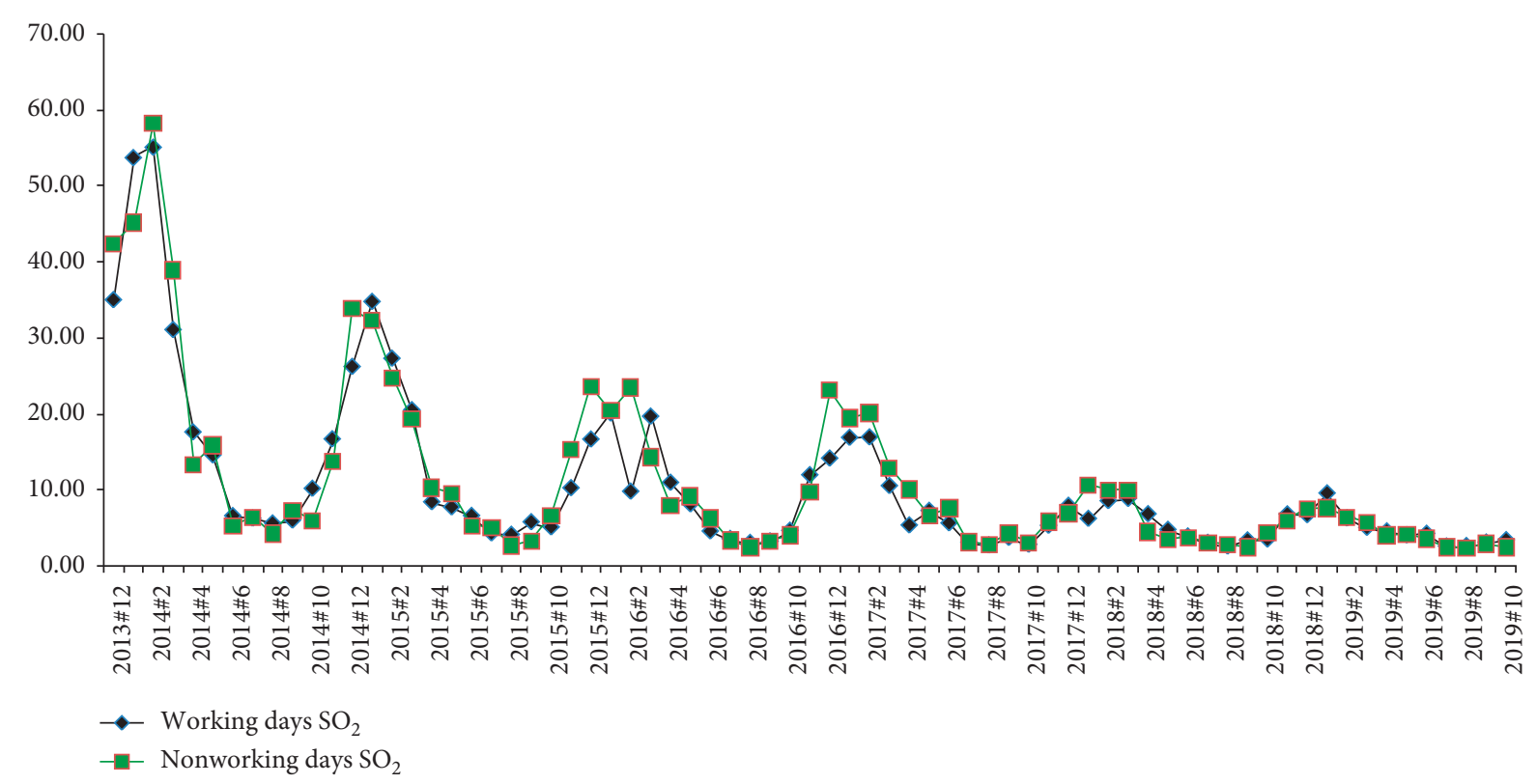

(d)

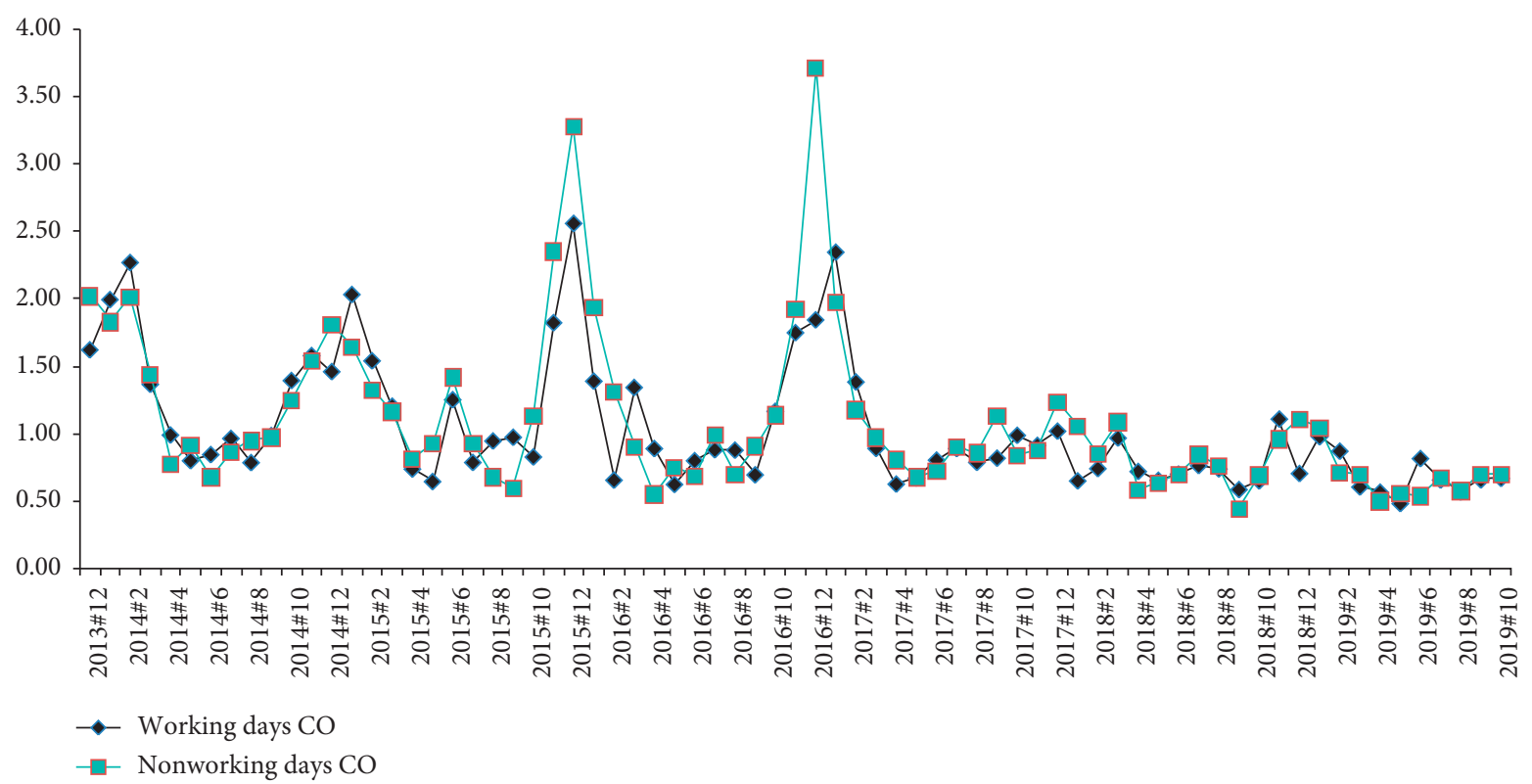

(e)

Figure 2: Continued. 


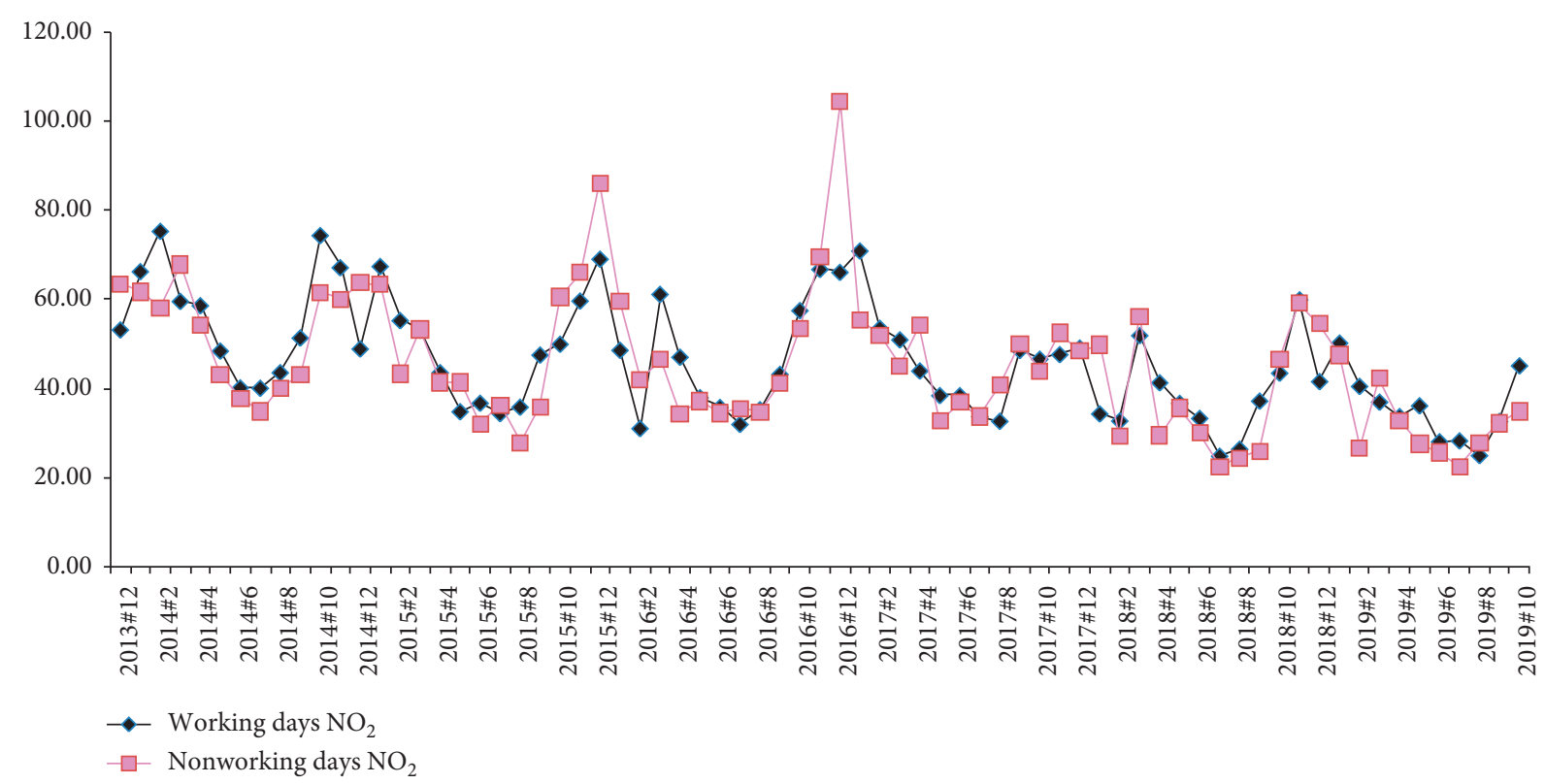

(f)

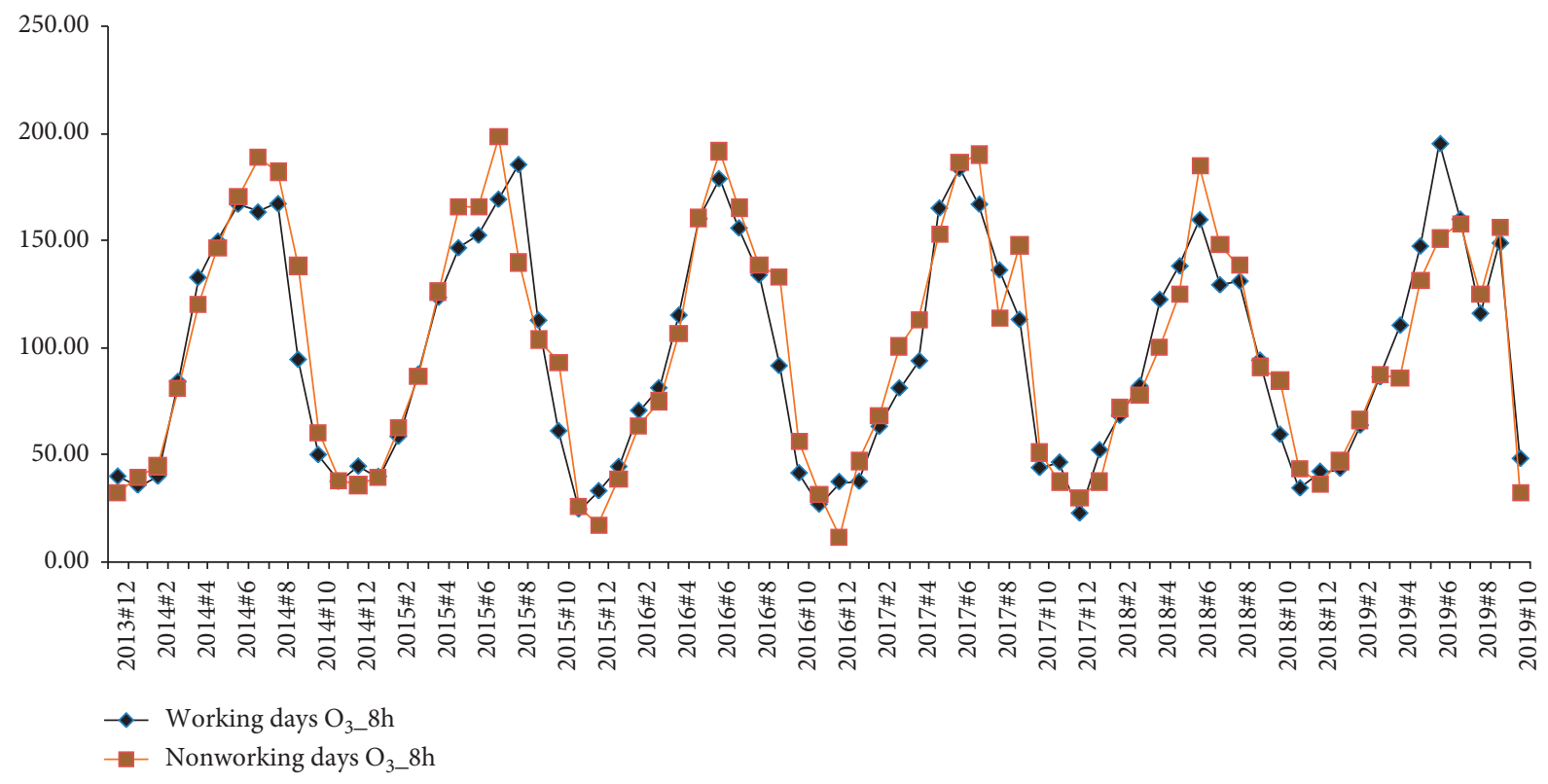

(g)

FIgURE 2: Comparison with working days and nonworking days.

value of $\mathrm{SO}_{2}$ was 78 , the maximum value of $\mathrm{CO}$ was 4.4 , the maximum value of $\mathrm{NO}_{2}$ was 120 , and the maximum value of $\mathrm{O}_{3}$ was 261 .

The average AQI was 106.16, the average PM2.5 was 66.58, the average PM10 was 93.42, the average $\mathrm{SO}_{2}$ was 14.06 , the average $\mathrm{CO}$ was 1.09 , the average $\mathrm{NO}_{2}$ was 44.16 , and the average $\mathrm{O}_{3}$ was 77.19 (Table 4).

During the period of 2014-2019, the fluctuations of $\mathrm{PM} 2.5, \mathrm{SO}_{2}$, and $\mathrm{CO}$ over the years showed a gradual wave decline $(p<0.05)$ regardless of the restricted or nonrestricted working days (Figure 3). However, $\mathrm{PM10}, \mathrm{NO}_{2}$, and $\mathrm{O}_{3}$ relatively fluctuated stably. In general, some peak values of AQI, PM2.5, PM10, $\mathrm{SO}_{2}, \mathrm{CO}$, and $\mathrm{NO}_{2}$ on nonrestricted working days were significantly higher than those on restricted working days $(p<0.01)$.

5.4. Long Holidays and Nonlong Holidays. In the sample cases, total long holidays (Spring Festival and National Day) were 84 days, accounting for $96.1 \%$ of the statistical day. Nonlong holidays (short holidays and working days other than the Spring Festival and National Day) totaled 2076 days, accounting for $3.90 \%$ of the calculated day. Long holiday: nonlong holiday $=24.7: 1$. The long holiday AQI maximum was 398, PM2.5 maximum was 345, PM10 maximum was $426, \mathrm{SO}_{2}$ maximum was 84 , $\mathrm{CO}$ maximum 
TABLE 4: Pearson correlation analysis of restricted working days and nonrestricted working days.

\begin{tabular}{|c|c|c|c|c|c|c|}
\hline & Peaks a & valleys $(n)$ & & & & \\
\hline & Restricted working days & Nonrestricted working days & $R^{2}$ & Pearson correlation coefficient & $X^{2}$ & $p$ \\
\hline AQI & 6 & 6 & 0.6693 & 19.0372 & 0.5319 & $>0.05$ \\
\hline PM2.5 & 6 & 6 & 0.4839 & 27.1479 & 0.0193 & $<0.05$ \\
\hline PM10 & 6 & 6 & 0.7578 & 41.6706 & 0.0977 & $>0.05$ \\
\hline $\mathrm{SO}_{2}$ & 6 & 6 & 0.8213 & 33.7825 & 0.5403 & $<0.05$ \\
\hline $\mathrm{CO}$ & 6 & 6 & 0.4631 & 27.3546 & 0.7999 & $<0.05$ \\
\hline $\mathrm{NO}_{2}$ & 6 & 6 & 0.7170 & 43.5918 & 0.4048 & $>0.05$ \\
\hline $\mathrm{O}_{3 \_} 8 \mathrm{~h}$ & 6 & 6 & 0.5894 & 32.3794 & 0.5447 & $>0.05$ \\
\hline
\end{tabular}

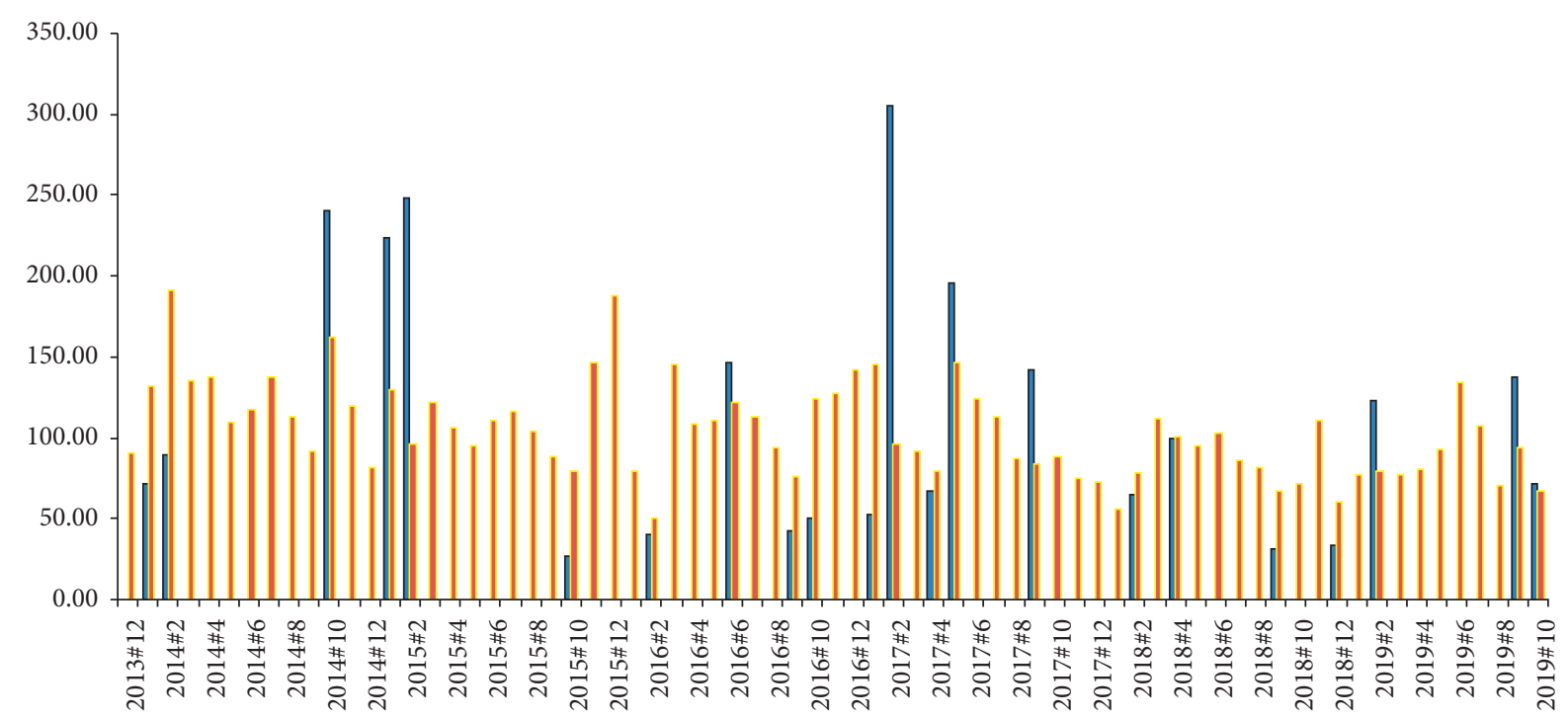

- Restricted working days AQI

$\square$ Nonrestricted working days AQI

(a)

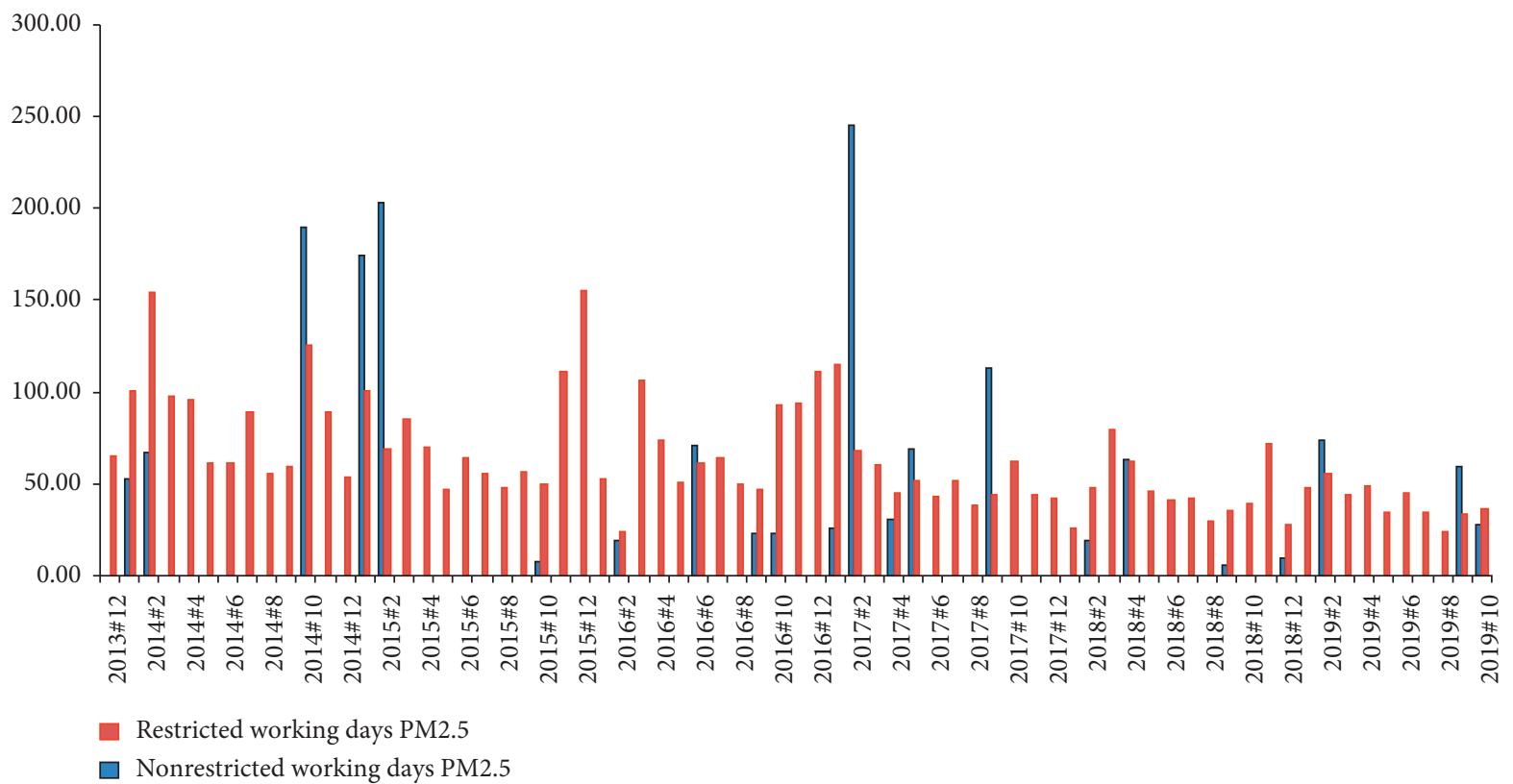

(b)

Figure 3: Continued. 


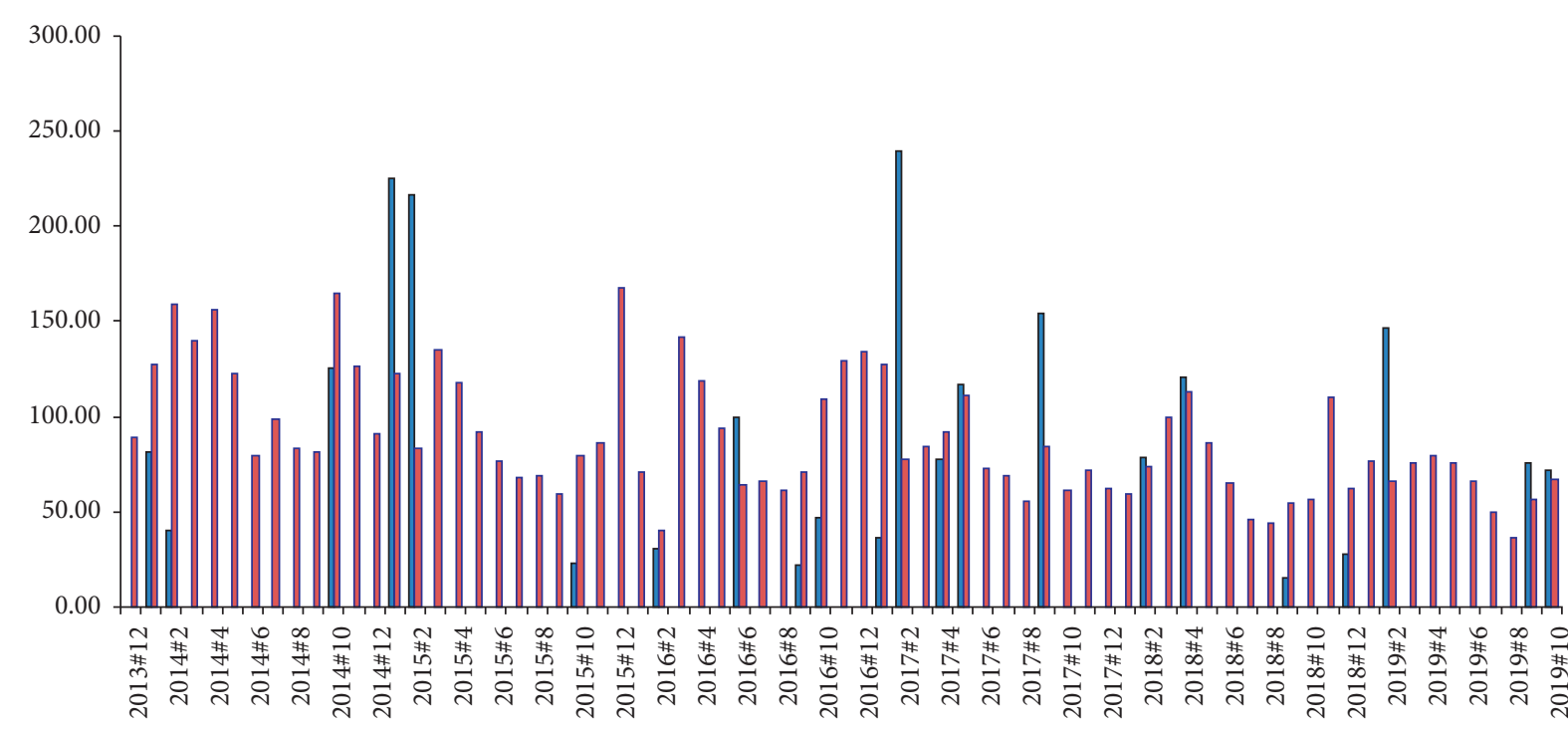

$\square$ Restricted working days PM10

$\square$ Nonrestricted working days PM10

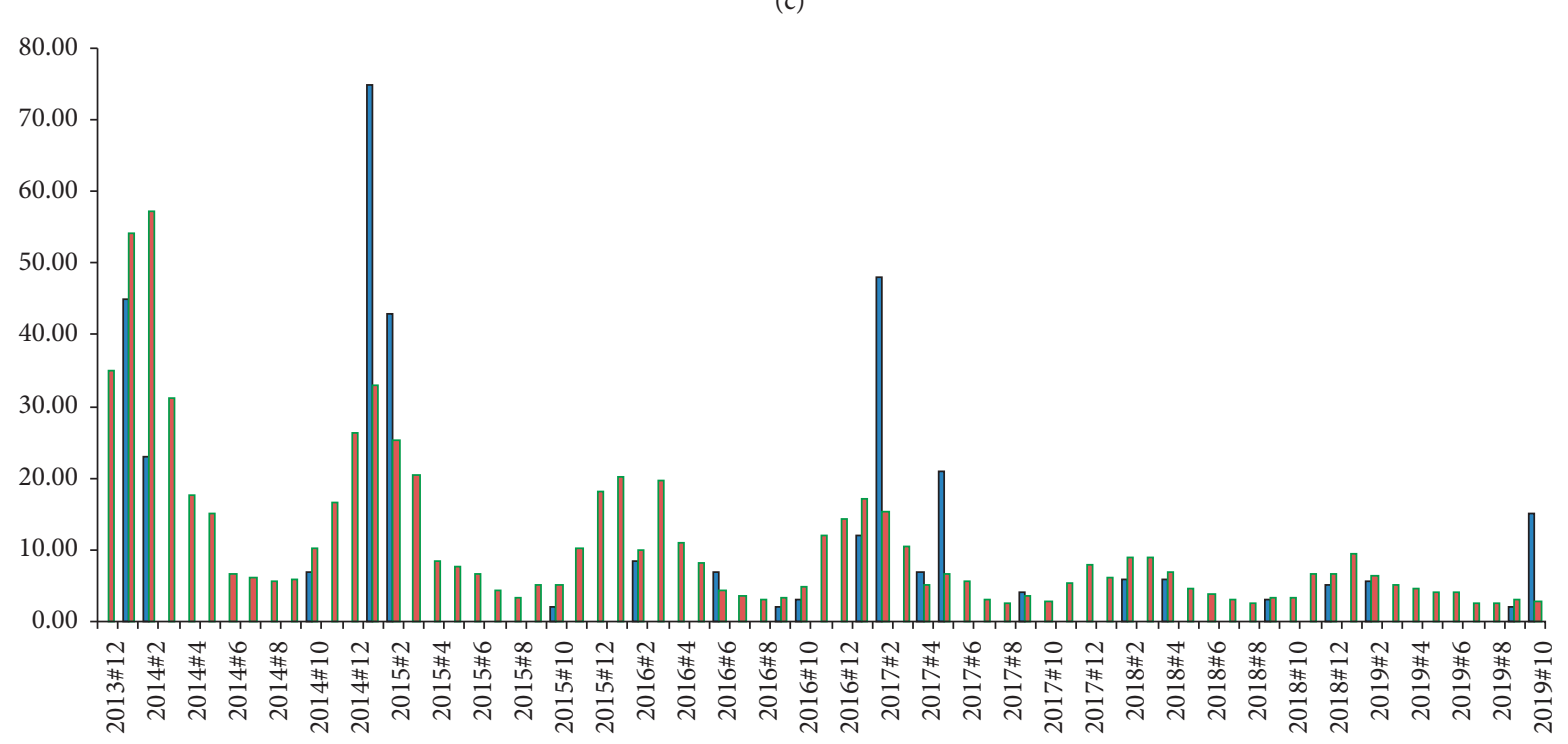

- Restricted working days $\mathrm{SO}_{2}$

$\square$ Nonrestricted working days $\mathrm{SO}_{2}$

(d)

FIgURE 3: Continued. 


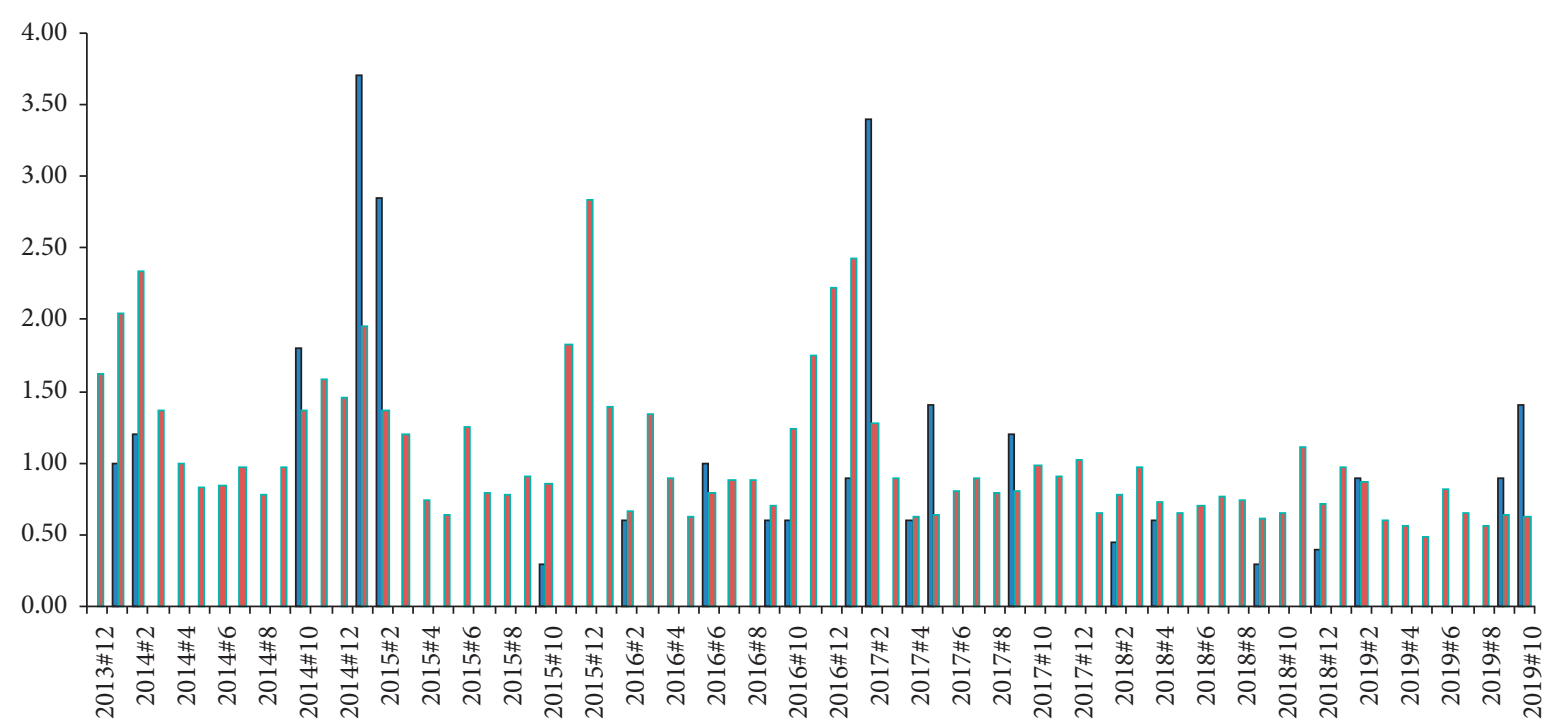

- Restricted working days $\mathrm{CO}$

$\square$ Nonrestricted working days CO

(e)

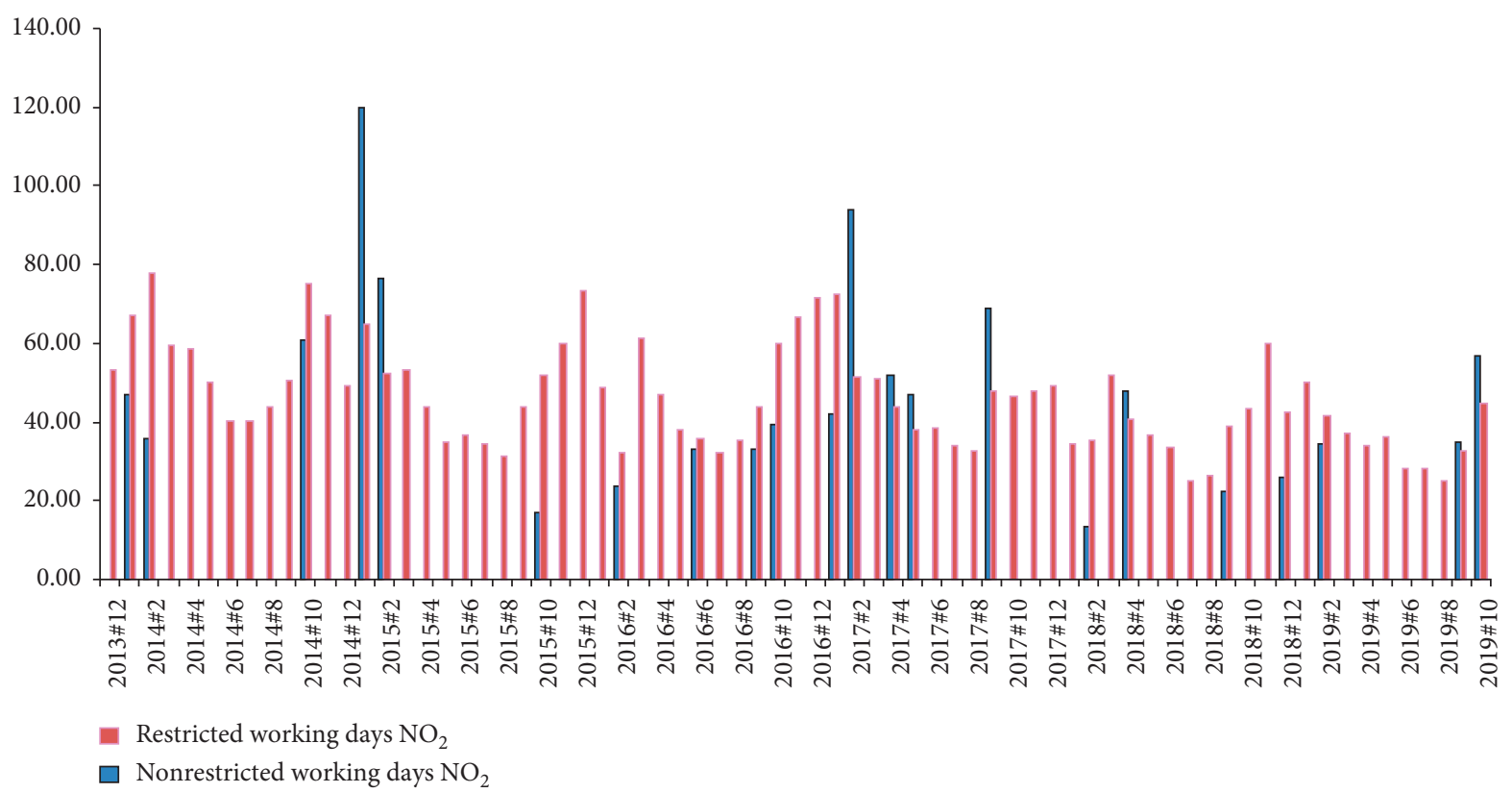

(f)

Figure 3: Continued. 


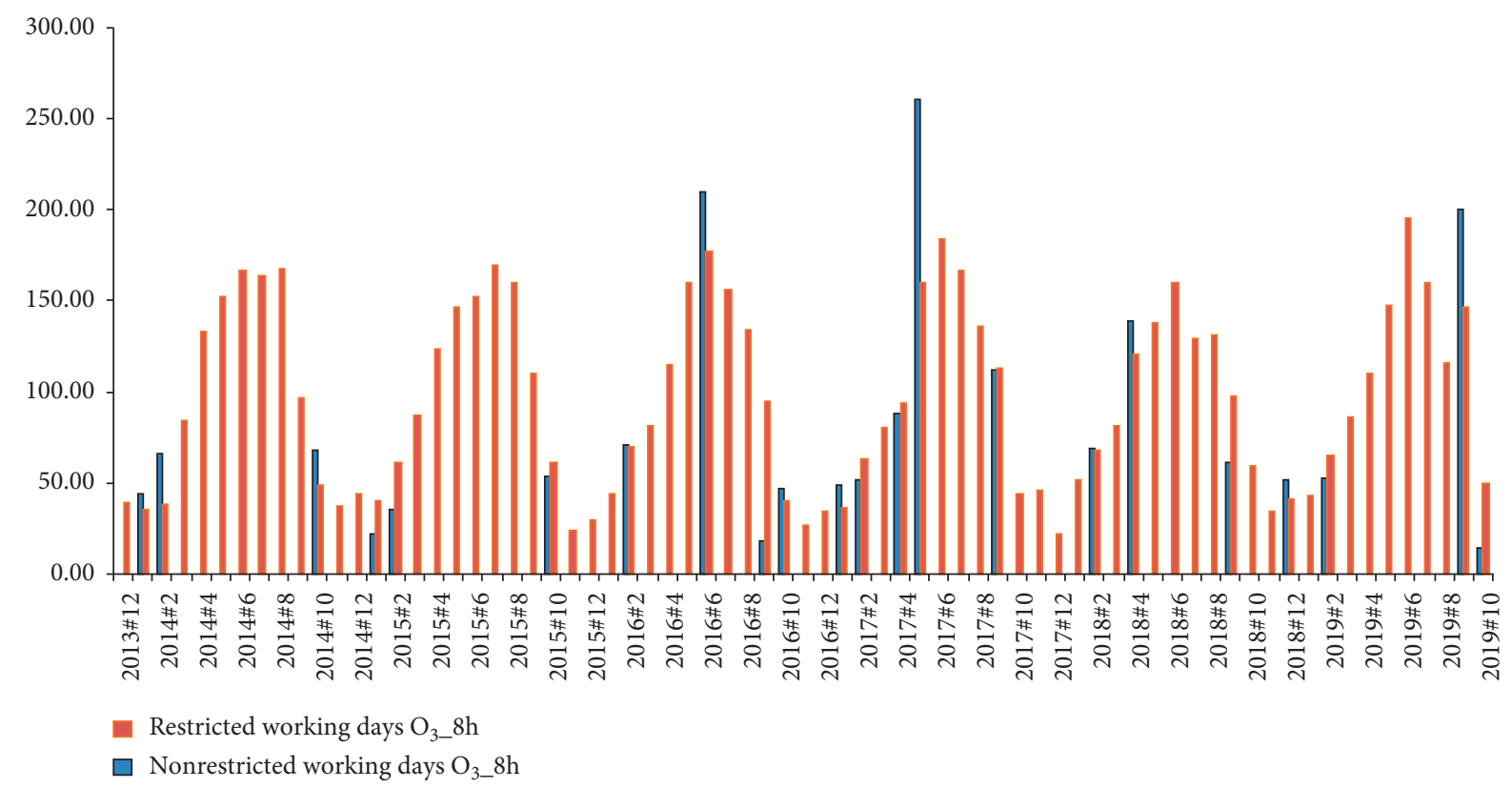

(g)

FIgURE 3: Comparison of restricted working days and nonrestricted working days.

was $3, \mathrm{NO}_{2}$ maximum was 86 , and $\mathrm{O}_{3}$ maximum was 200 . The average AQI was 107.49, the average PM2.5 was 76.92, the average PM10 was 96.21, the average $\mathrm{SO}_{2}$ was 13.63 , the average $\mathrm{CO}$ was 1.04 , the average $\mathrm{NO}_{2}$ was 40.67 , and the average value of $\mathrm{O}_{3}$ was 66.05. Among them, the nonlong vacation (short holidays and working days except for the Spring Festival and National Day) was 500, PM2.5 maximum was $477, \mathrm{PM} 10$ maximum was $550, \mathrm{SO}_{2}$ maximum was 133, $\mathrm{CO}$ maximum was $8, \mathrm{NO}_{2}$ maximum was 155 , and $\mathrm{O}_{3}$ maximum was 311 . The average AQI was 106.66 , the average PM2.5 was 64.21 , the average PM10 was 90.20, the average $\mathrm{SO}_{2}$ was 10.57 , the average $\mathrm{CO}$ was 1.05 , the average $\mathrm{NO}_{2}$ was 45.83 , and the average $\mathrm{O}_{3}$ was 99.52 (Table 5).

From 2014 to 2019, the fluctuations of AQI, PM2.5, $\mathrm{PM} 10, \mathrm{SO}_{2}$, and $\mathrm{CO}$ in the past few years have shown a gradual wave decline between long vacation and nonlong vacation $(p<0.05)$ (Figure 4$)$. The fluctuation performance of $\mathrm{O}_{3}$ was overall relatively stable $(p<0.05)$. In general, there was no significant difference between the peak values of AQI, PM2.5, $\mathrm{PM} 10, \mathrm{SO}_{2}, \mathrm{CO}$, and $\mathrm{NO}_{2}$ during long vacations and nonlong vacations $(p<0.05)$.

\section{Discussion}

It was once believed that, among all air pollution control measures, motor vehicle restrictions were due to its low cost, simplicity, and low public input [13]. Faced with Beijing's long-term tail-limit policy, most residents, especially those who just need it, would respond accordingly as renting their Beijing-brand vehicles, travelling by number, buying nonBeijing passenger vehicles, or by purchasing non-Pekingbrand vehicles and so forth so as to circumvent the tail-limit policy by alternative means.
It was also believed that limit policy has led to a significant increase in $\mathrm{CO}$ concentration due to the ban on stimulating sales of private cars $[14,15]$. With Mexico City data, Davis found that traffic restrictions did not significantly increase the use of public transportation, but rather significantly increased the proportion of high-emission used cars in motor vehicle sales. What is more, traffic restrictions also were reasoned that the restricted traffic policy did not achieve the expected results [13].

According to the data analysis above, it was found that the fluctuation of AQI, PM2.5, PM10, $\mathrm{SO}_{2}, \mathrm{CO}$, and $\mathrm{O}_{3}$ generally decreased from 2014 to 2019 . The amplitude is 6 , which is highly consistent with the annual performance. Therefore, the season is an important parameter affecting most indicators of Beijing's air quality. Except for $\mathrm{O}_{3}$, the influence of season on AQI, PM2.5, PM10, $\mathrm{SO}_{2}$, and $\mathrm{CO}$ is relatively stable. That the performance of $\mathrm{O}_{3}$ is relatively stable indicates that the production of $\mathrm{O}_{3}$ is relatively independent of human factors! The real reason remains to be further analyzed. Except for $\mathrm{O}_{3}$, comparing peaks of AQI, $\mathrm{PM}$ 2.5, $\mathrm{PM} 10, \mathrm{SO}_{2}, \mathrm{CO}$, and $\mathrm{NO}_{2}$ on the last 4 and 9 limit days, it was revealed that dynamic peak control of AQI, $\mathrm{PM}$ 2.5, PM10, $\mathrm{SO}_{2}, \mathrm{CO}$, and $\mathrm{NO}_{2}$ at 4 and 9 limit days is significantly worse than the non- 4 and 9 limit days. The fact indicated that the air quality of the 4 and 9 limit days is generally worse than the non-4 and 9 limit days. At the same time, studies once showed that after controlling other variables, compared with the changing trend of busy days from the nontraffic hours to traffic hours with the nontraffic days to the busy days, The PM2.5 concentration of nontraffic hours of tail 4 and 9 limit days was significantly increased from the nontraffic hours to traffic hours. The relative increase was $9.46 \%$ above the average PM2.5 concentration. 
TABle 5: Pearson correlation analysis of long holidays (Spring Festival and National Day) and nonlong holidays.

\begin{tabular}{lccccc}
\hline & \multicolumn{2}{c}{ Peaks and valleys $(n)$} & \multirow{2}{*}{$R^{2}$} & Pearson correlation coefficient & $X^{2}$ \\
& Long holidays & Nonlong holidays & & & $p$ \\
\hline AQI & 6 & 6 & 0.2393 & 29.4367 & 0.3800 \\
PM2.5 & 6 & 6 & 0.5366 & 20.1743 & $>0.05$ \\
PM10 & 6 & 6 & 0.7005 & 32.7058 & $<0.05$ \\
$\mathrm{SO}_{2}$ & 6 & 6 & 0.6511 & 29.0154 & 0.0362 \\
$\mathrm{CO}$ & 6 & 6 & 0.5547 & 36.4589 & 0.5513 \\
$\mathrm{NO}_{2}$ & 6 & 6 & 0.2722 & 16.2163 & $<0.05$ \\
$\mathrm{O}_{3 \_} 8 \mathrm{~h}$ & 6 & 6 & 0.6696 & 18.7781 & 0.7135 \\
\hline
\end{tabular}

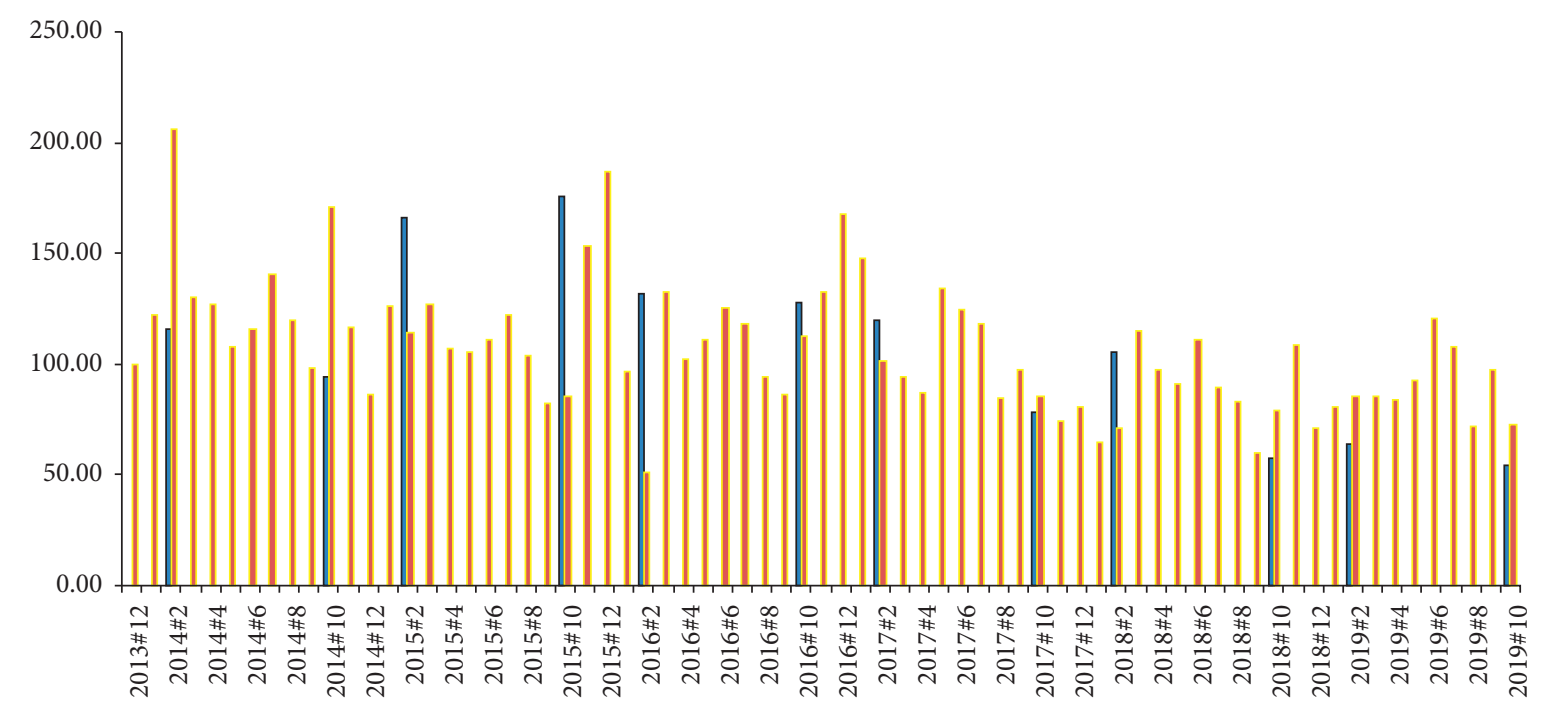

$\square$ Long holidays (Spring Festival and National Day) AQI

- Nonlong holidays AQI

(a)

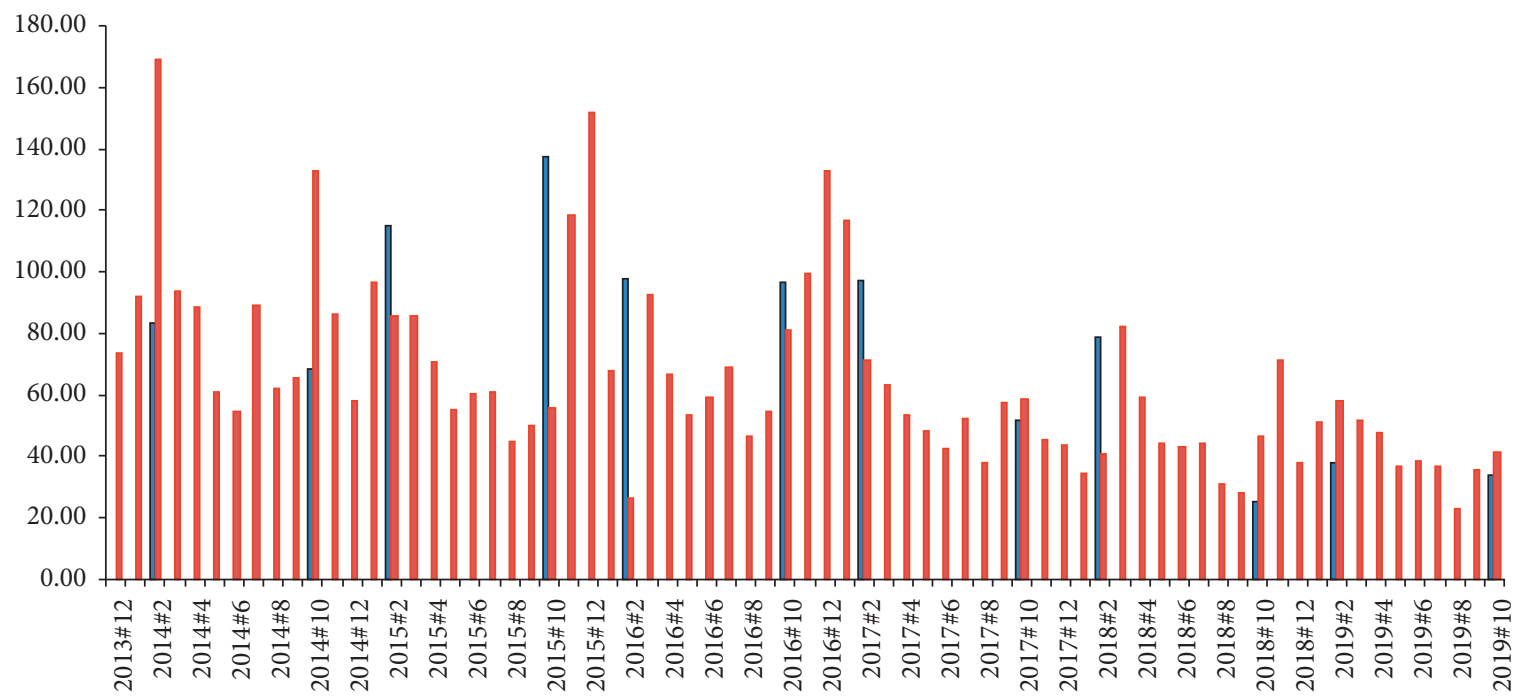

$\square$ Long holidays (Spring Festival and National Day) PM2.5

Nonlong holidays PM2.5

(b)

Figure 4: Continued. 


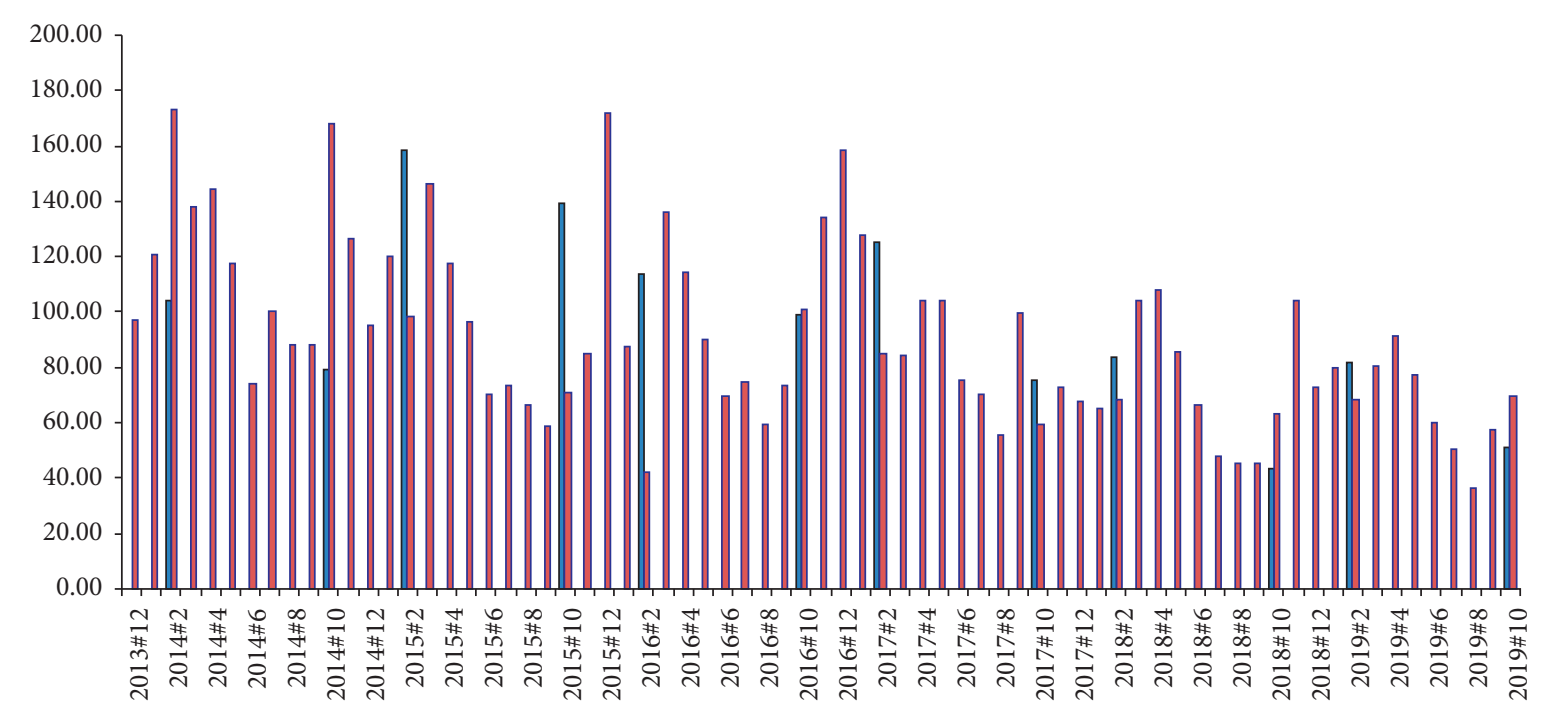

$\square$ Long holidays (Spring Festival and National Day) PM10

$\square$ Nonlong holidays PM10

(c)

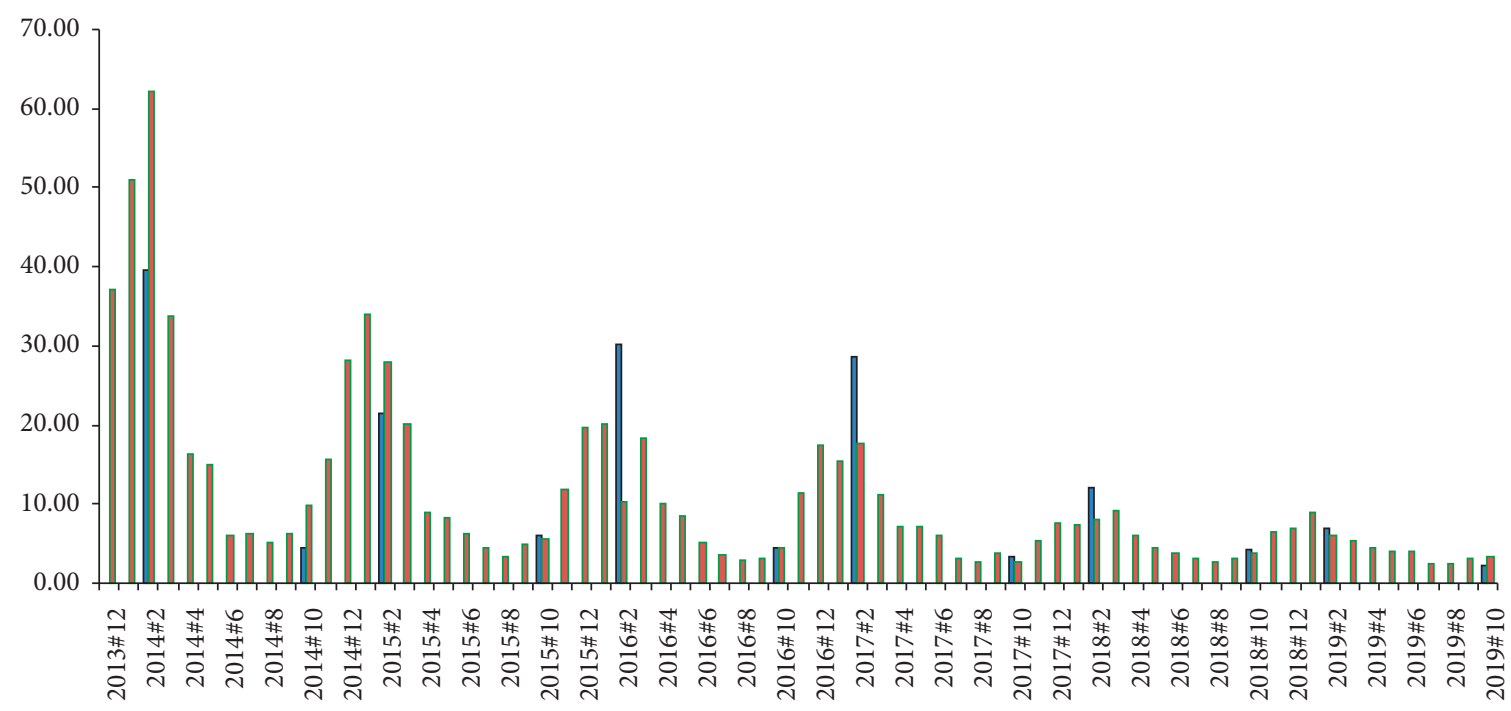

$\square$ Long holidays (Spring Festival and National Day) $\mathrm{SO}_{2}$

- Nonlong holidays $\mathrm{SO}_{2}$

(d)

Figure 4: Continued. 


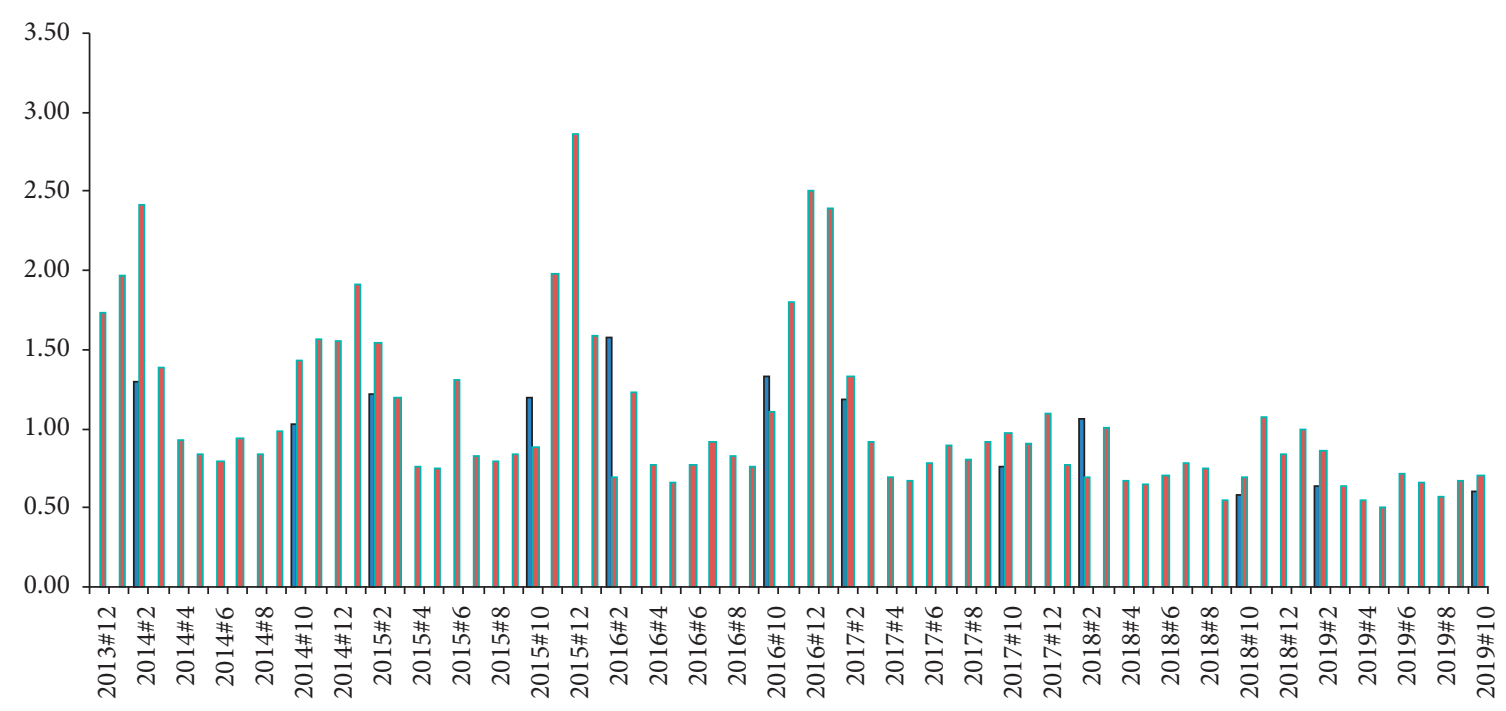

$\square$ Long holidays (Spring Festival and National Day) CO

- Nonlong holidays CO

(e)

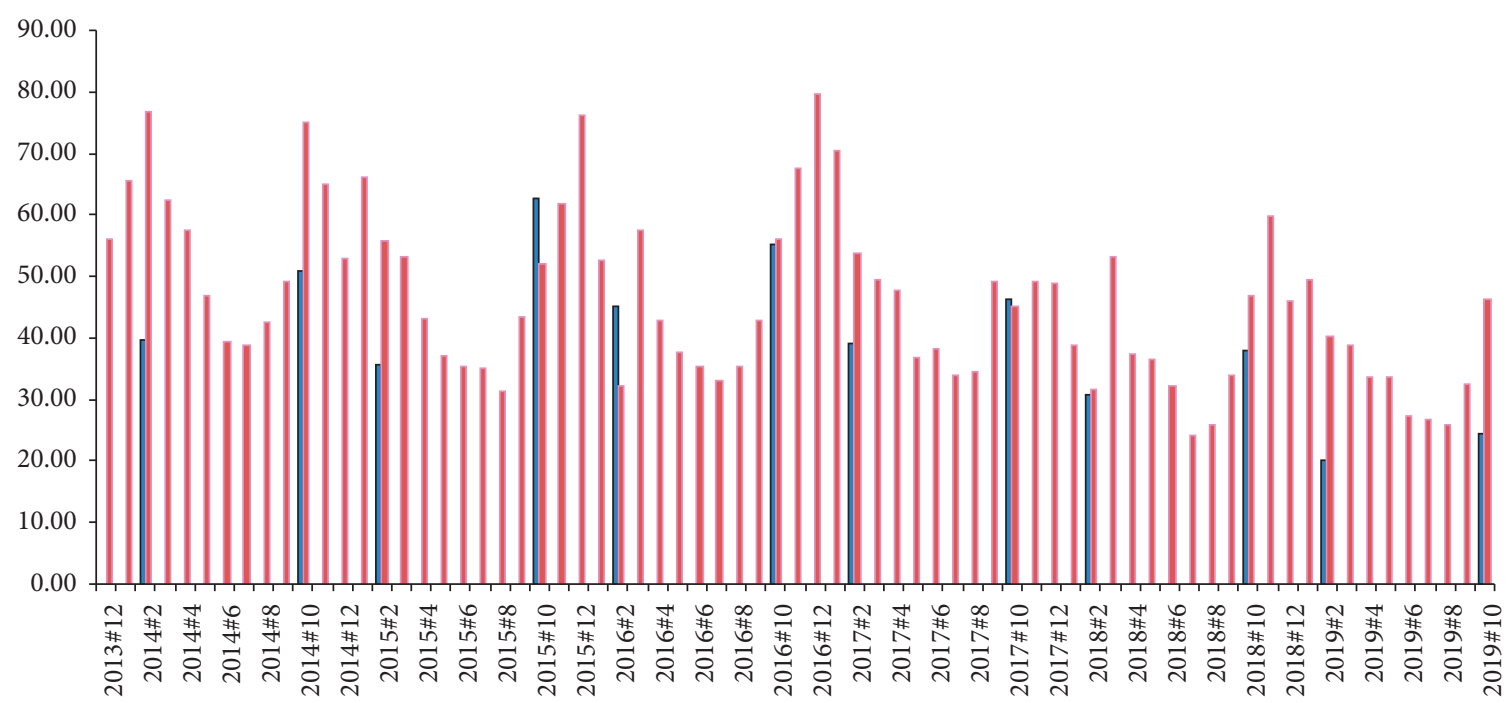

$\square$ Long holidays (Spring Festival and National Day) $\mathrm{NO}_{2}$

- Nonlong holidays $\mathrm{NO}_{2}$

(f)

Figure 4: Continued. 


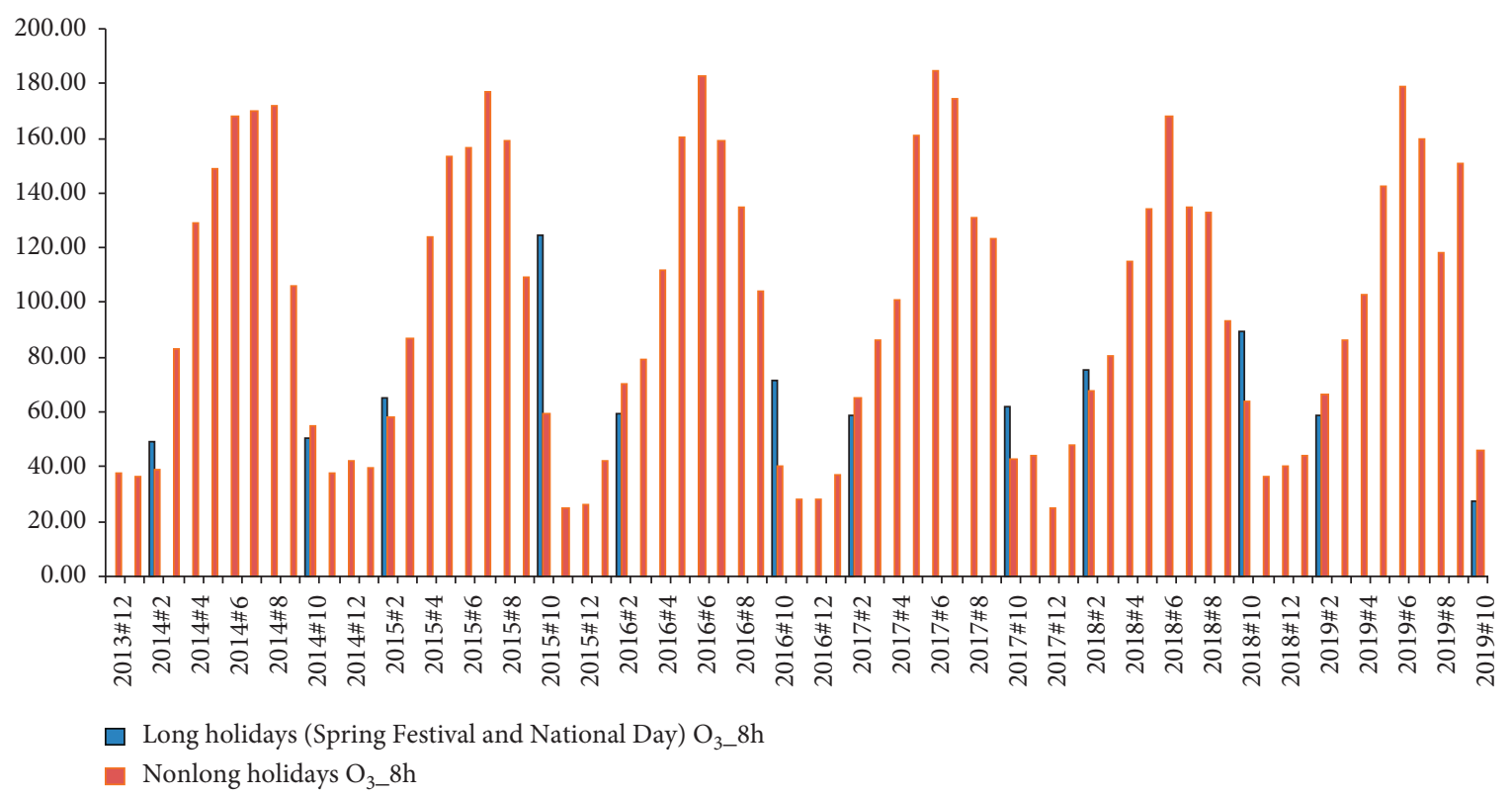

(g)

FIGURE 4: Comparison with long holidays and nonlong holidays.

Combining the proportion of vehicles with tail number 4 in Beijing (in fact, the whole of China has similar cultural foundations as a whole), it can be considered that different numbers of tail number restrictions affect air quality significantly.

Based on Figures 1-4, the median of the dynamic curves of AQI, PM2.5, PM10, $\mathrm{SO}_{2}, \mathrm{CO}$, and $\mathrm{NO}_{2}$ has gradually decreased over the past six years. In the case of stability under the control of Beijing motor vehicles, it is obvious that the impact of automobile exhaust on air quality is relatively limited. Collecting Beijing samples from 2009 to 2010, the six sources of PM2.5 were analyzed with the PMF method. It was found that industrial pollution accounts for $28 \%$, and the impact of automobile exhaust is less than $4 \%$ [16].

Comparing the data of all working days and all nonworking days, one clear and progressive wave-like decline was shown with the air quality indicators AQI, PM2.5, $\mathrm{PM} 10, \mathrm{SO}_{2}, \mathrm{CO}, \mathrm{NO}_{2}$, and $\mathrm{O}_{3}$. The number of motor vehicles was found with limited effects on $\mathrm{SO}_{2}$ and $\mathrm{O}_{3}$. However, the number of vehicles travelling differently found a significant impact on the peak values of AQI, PM2.5, PM10, CO, and $\mathrm{NO}_{2}$. Therefore, the restrictions on motor vehicles have an objective impact on air AQI, PM2.5, PM10, CO, and $\mathrm{NO}_{2}$. Contrary to the conclusions of this article, Yuan Xiaoling and others used breakpoint regression and double-difference analysis to test the effect of Xi'an's restricted traffic policy on improving air quality [17]. The effect of the traffic restriction policy was adopted in Lanzhou on such four air pollutants as $\mathrm{NO}_{2}, \mathrm{O}_{3}, \mathrm{PM} 10$, and CO. Results found that the traffic restriction policy had little effect on PM10 and CO and a significant effect on reducing the concentration of $\mathrm{NO}_{2}$ and $\mathrm{O}_{3}[18]$.

Regardless of restricted working days or nonrestricted working days, a gradual wave-like decreasing performance was shown with the fluctuations of PM2.5, $\mathrm{SO}_{2}$, and $\mathrm{CO}$ in Beijing in recent years. The decline in the overall trend is mainly due to the government's administrative measures and the increase in public awareness. Such peak values of AQI, PM2.5, PM10, $\mathrm{SO}_{2}, \mathrm{CO}$, and $\mathrm{NO}_{2}$ on nontraffic working days were significantly higher than those on nontraffic working days. The fact indicated that motor vehicles do indeed have a certain atmospheric impact on AQI, $\mathrm{PM}$ 2.5, $\mathrm{PM} 10, \mathrm{SO}_{2}, \mathrm{CO}$, and $\mathrm{NO}_{2}$. Collecting samples from Beijing in 2000, the CMB (chemical mass balance receptor model) method was used in analysis; it points out that soil dust is the main source of PM2.5, accounting for 20\% [19]. Beijing sample 2000 was analyzed by PMF (Positive Matrix Factor) method; it was found that coal combustion accounted for $19 \%$, while automobile exhaust accounted for $6 \%$ among the eight main sources of PM2.5 [20]. Their results are consistent with the conclusions of this article. At the same time, it was confirmed that the motor vehicle restriction policy cannot promote the use of public transportation by car owners [21], which illustrates the existence of evasive behavior by car owners. The evasive behavior of car owners will underestimate the estimates of the effects of motor vehicle restrictions. What is more, it was believed that long-term restrictions will increase air pollution [22]. Based on this theory, it is not obviously unscientific to improve the air quality of Beijing in recent years.

According to the 2014-2019 analysis of long holidays (Spring Festival and National Day) and nonlong holidays (short holidays and working days other than the Spring Festival and National Day), AQI, PM2.5, PM10, $\mathrm{SO}_{2}, \mathrm{CO}$, and $\mathrm{NO}_{2}$ dynamics of the long holidays (Spring Festival and National Day), there is no significant difference between the peak performance and nonlong holidays (short holidays and working days except for the Spring Festival and National 
Day). Combined with the fact that some peaks of the dynamic performance of AQI, PM2.5, PM10, $\mathrm{SO}_{2}, \mathrm{CO}$, and $\mathrm{NO}_{2}$ on nontraffic working days are significantly higher than those on restricted working days, there are peak times with AQI, PM2.5 PM10, $\mathrm{SO}_{2}, \mathrm{CO}$, and $\mathrm{NO}_{2}$ when considering motor vehicles in Beijing area. This time should be between 3 and 5 days, or 72-120 hours.

\section{Conclusion}

In this study, dynamic changes of AQI, PM2.5, PM10, $\mathrm{SO}_{2}$, $\mathrm{CO}, \mathrm{NO}_{2}$, and $\mathrm{O}_{3}$ were analyzes with the tail number of 4 and 9 days and nontail number of 4 and 9 days, nonworking days, working days and nonworking days, and long holidays (Spring Festival and National Day) and nonlong holidays (except for Spring Festival) in Beijing. Short holidays and working days outside the National Day). The air quality of 49 lines is worse than that of non-49 lines. Motor vehicles restricted in traffic found an objective effect on air AQI, PM2.5, PM10, CO, and $\mathrm{NO}_{2}$, whereas there was no difference in $\mathrm{O}_{3}$. Some peak values of AQI, PM2.5, PM10, $\mathrm{SO}_{2}$, $\mathrm{CO}$, and $\mathrm{NO}_{2}$ on nonrestricted working days are significantly higher than those on restricted working days. At the same time, there was a peak time with motor vehicles impact on AQI, PM2.5, PM10, $\mathrm{SO}_{2}, \mathrm{CO}$, and $\mathrm{NO}_{2}$ in Beijing. This time should be between 3 and 5 days, or 72-120 hours.

\section{Data Availability}

The air pollution index data included daily averages of such five main air pollutants as $\mathrm{PM} 2.5, \mathrm{PM} 10, \mathrm{SO}_{2}, \mathrm{CO}, \mathrm{NO}_{2}$, and $\mathrm{O}_{3}$ concentrations and the air pollution index AQI, routinely monitored in China. Data came from the website of the Chinese Ministry of Ecology and Environment (https:// www.aqistudy.cn/).

\section{Conflicts of Interest}

The authors declare that they have no conflicts of interest.

\section{References}

[1] K. Coneus and C. K. Spiess, "Pollution exposure and child health: evidence for infants and toddlers in Germany," Journal of Health Economics, vol. 31, no. 1, p. 180196, 2012.

[2] J. Currie, E. A. Hanushek, E. M. Kahn, M. Neidell, and S. G. Rivkin, "Does pollution increase school absences?" Review of Economics and Statistics, vol. 91, no. 4, pp. 682-694, 2009.

[3] M. J. Neidell, "Air pollution, health, and socio economic status: the effect of outdoor air quality on childhood asthma," Journal of Health Economics, vol. 23, no. 6, Article ID 12091236, 2004.

[4] Y. Huang, Q. Yan, and C. Zhang, "Spatial-----Temporal distribution characteristics of PM2.5 in China in 2016," Journal of Geovisualization and Spatial Analysis, vol. 2, p. 12, 2018.

[5] M. Filonchyk and H. Yan, "The characteristics of air pollutants during different seasons in the urban area of Lanzhou, Northwest China," Environmental Earth Science, vol. 77, p. 763, 2018.
[6] S. Tanaka, "Environmental regulations on air pollution in China and their impact on infant mortality," Journal of Health Economics, vol. 42, Article ID 90103, 2015.

[7] M. Greenstone and R. Hanna, "Environmental regulations, air and water pollution, and infant mortality in India," American Economic Review, vol. 104, no. 10, Article ID 30383072, 2014.

[8] M. Auffhammer and R. Kellogg, "Clearing the air? The effects of gasoline content regulation on air quality," American Economic Review, vol. 101, no. 6, Article ID 26872722, 2011.

[9] K. Sun, "Study on the effect of smog treatment on motor vehicle emission standards-analysis based on breakpoint regression design," Soft Science, vol. 11, 2017.

[10] http://www.ccn.com.cn/html/news/xiaofeiyaowen/2017/ 0813/23764.html.

[11] W. Zhang, "A comparative study of the selection methods of approximate factor model factors," M. S. thesis, Shanghai Normal University, Shanghai, China, 2019.

[12] Y. Liu and Y. Zhang, "Does motor vehicle restriction policy reduce urban air pollution? -- An Empirical Test Based on quasi experiment in Shandong Province (China)," Journal of Shandong University (philosophy and social sciences edition), vol. 4, 2019.

[13] L. W. Davis, "The effect of driving restrictions on air quality in Mexico city," Journal of Political Economy, vol. 116, no. 1, p. 3881, 2008.

[14] F. Liu, G. Andrienko, N. Andrienko et al., "Citywide traffic analysis based on the combination of visual and analytic approaches," Journal of Geovisualization and Spatial Analysis, vol. 4, p. 15, 2020.

[15] F. Gallego, J. P. Montero, and C. Salas, "The effect of transport policies on car use: evidence from Latin American cities," Journal of Public Economics, vol. 107, p. 4762, 2013.

[16] R. Zhang, J. Jing, J. Tao et al., "Chemical characterization and source apportionment of Pm2. 5 in beijing: seasonal perspective," Atmospheric Chemistry and Physics, vol. 13, pp. 7053-7074, 2013.

[17] X. Yuan, H. Li, and W. Yang, "Can the motor vehicle limit policy effectively improve the air quality in Xi'an?" Statistics and Information Forum, vol. 6, 2018.

[18] W. Qi, H. Huang, and S. Wang, "Evaluation of air quality effect of motor vehicle restriction policy-a data integration analysis with Lanzhou as a typical model," Statistics and Information Forum, vol. 9, 2015.

[19] M. Zheng, L. G. Salmon, J. J. Schauer et al., "Seasonal trends in PM2. 5 source contributions in beijing,China," Atmospheric Environment, vol. 39, no. 22, pp. 3967-3976, 2005.

[20] Y. Song, Y. Zhang, S. Xie et al., "Source apportionment of PM2. 5 in beijing by positive matrix factorization," Atmospheric Environment, vol. 40, no. 8, pp. 1526-1537, 2006.

[21] Y. Liu, Z. Hong, and Y. Liu, "Do driving restriction policies effectively motivate commuters to use public transportation," Energy Policy, vol. 90, Article ID 253261, 2016.

[22] W. Zhang, C. Lawell, and V. I. Umanskaya, "The effects of license plate based driving restrictions on air quality: theory and empirical evidence," Journal of Environmental Economics and Management, vol. 82, p. 181220, 2017. 